Article

\title{
Sustainability Evaluation Based on a Three-Dimensional Ecological Footprint Model: A Case Study in Hunan, China
}

\author{
Chuxiong Deng ${ }^{1}$, Zhen Liu ${ }^{1}$, Rongrong $\mathrm{Li}^{1}$ and $\mathrm{Ke} \mathrm{Li}^{2}{ }^{2} * \mathbb{C}$ \\ 1 College of Resources and Environmental Sciences, Hunan Normal University, Changsha 410081, China; \\ dcxppd@163.com (C.D.); m15674986040@163.com (Z.L.); leerong520@sina.com (R.L.) \\ 2 Key Laboratory of Computing and Stochastic Mathematics (Ministry of Education of China), School of \\ Mathematics and Statistics, Hunan Normal University, Changsha 410081, China \\ * Correspondence: likekent1208@163.com; Tel.: +86-731-8883-8057
}

Received: 30 October 2018; Accepted: 27 November 2018; Published: 29 November 2018

\begin{abstract}
Under the concept of green development, the promotion of ecological sustainable development capability has become an important policy objective of the Chinese government. Based on the three-dimensional ecological footprint model, this paper analyzes the ecological footprint, ecological carrying capacity, and ecological sustainable development capacity of Hunan province from 2005 to 2015. The results show that the total ecological footprint of Hunan increases from 2005 to 2015, in which the forest land ecological footprint accounts for the largest proportion. The ecological footprint depth is always greater than 1 , indicating that Hunan has been in a state of ecological deficit; in the context of the distribution, the ecological pressure of Hunan shows a "high in surround while low in central" pattern. The results about the ecological footprint diversity index show that although the ecosystem of Hunan is stability, the level of eco-economic development ability is low. The ecological efficiency represented by GDP per unit of ecological footprint shows that Hunan's ecological efficiency increases with an average rate of $13.12 \%$ annually during $2005-2015$ because of the improvement of the factor substitution.
\end{abstract}

Keywords: ecological footprint; ecological carrying capacity; ecological sustainable development capacity; ecological efficiency; Hunan

\section{Introduction}

Humanity's survival and development depend on the ecological environment, but also greatly affect the ecological environment. Since the Industrial Revolution, the large-scale destruction of the natural environment, the continuous deterioration of the relationship between humans, nature, and global warming have aroused great attention of the international community. Sustainable development has become the consensus of the whole society. In recent years, the Chinese government has vigorously promoted the construction of ecological civilization, and proposed to build "the modernization of harmony and symbiosis between man and nature in order to provide more high-quality ecological products to meet the increasing needs of beautiful ecological environment". In December 2017, the Chinese government first published the regional green development index, which is considered as a major measure for the central government to strengthen the construction of ecological civilization and highlight the assessment of sustainable development goals.

The sustainable development of ecological environment needs to take into account the regeneration and substitution ability of natural resources, the circulation and purification ability of life support system and the protection of biodiversity, etc. Therefore, how to quantify the 
human demands and supply for natural capital are the priority topics in the field of sustainable development research. The ecological footprint method was initially proposed by Wackernagel and Rees, quantitative evaluating the degree of sustainable utilization of resources through accounting and comparing the gap between the demand of human economic system for natural ecosystem services and the carrying capacity of natural ecosystem. Because of its visual and clear calculation results and regional comparability, it has been widely used in the measurement of sustainable development [1]. The researchers also found that the ecological footprint is closely related to the level of economic development, so the ecological footprint can be used to effectively measure the level of economic development and ecological efficiency of a country [2-5].

The Chinese government has incorporated the ability of ecological sustainable development into the assessment target of government. Therefore, the scientific interests of this study focused on the following: (1) evaluating the ecological footprint (EF), ecological carrying capacity, ecological sustainable development capacity, and ecological efficiency of Hunan Province-a typical province in central China-from 2006 to 2015, and comprehensively using the ecological sustainable development index, based on a three-dimensional (3D) ecological footprint model. (2) Furthermore, measuring and evaluating the ecological efficiency of Hunan and then decomposing the ecological efficiency into the change of total factor productivity and the change of factor substitution, taking the output index and ecological index into consideration synthetically to explore the reasons for the change of ecological efficiency. This study is so meaningful that it provides an academic reference of ecological sustainability analysis, and it also provides a scientific basis for sustainable development strategies that can be employed in construction of the ecological civilization in other provinces.

\section{Literature Review}

The ecological footprint model, which has been used to evaluate the ecological sustainability of China or a typical region in a large number of literatures sources, is a method which tries to calculate the degree of human utilization of natural data and the function of life support services provided by nature to human beings. Wu and Liu [6] analyzed the imbalances, inequities and pressures of EF of China's 30 provinces in 2007. The results showed that most provinces presented EF-deficits, and the carbon footprint in the secondary sector was the main embodied EF of the flows among the provinces responsible for inequities. He, et al. [7] calculated the ecological footprint of six cities (Nanchang, Jingdezhen, Jiujiang, Xinyu, Yingtan, and Fuzhou) in the Poyang Lake Area in Jiangxi province from 1991 to 2010. Their results reveal that the contribution of ecological footprint to economic growth is very low, meaning that the efficiency of ecological resources utilization is low. Wang, et al. [8] introduced a multi-scale assessment framework for evaluating water resource sustainability based on the ecological pressure index (EPI), and using it to evaluate the sustainability of water resources in Liaohe River Basin. Li, et al. [9] developed a consumption footprint pressure index (CFPI) and a production footprint pressure index (PFPI) based on the ecological footprint concept, and developed an ecological footprint contribution index (EFCI) to evaluate the ecological security of the typical prairie including four prefecture-level cities in China (Abag County, East Ujimqin County, West Ujimqin County, and Xilinhot City). Gu, et al. [10] proposed a modified EF model by adapting equivalence and yield factors in context of net primary productivity (NPP) from the Miami model, and use it to evaluate the sustainable development of urban areas in the middle stream of the Yangtze River Basin from 2000 to 2010. Li, et al. [11] assessed the sustainability of the drylands in northern China (DNC) according to their changes in EF from 1990 to 2010. Yin, et al. [12] analyzed the variations in the EFs and regional development capacity of five provinces (Shanxi, Qinghai, Ningxia, Shanxi, and Gansu) in Northwest China in 2005-2014. Taking the Beijing-Tianjin-Hebei (BTH) region as the research object, Xie, et al. [13] quantify and map the quality and variation tendency of water yield, sediment retention, carbon sequestration, and grain productive capacity from individual ecological-functional zones in 2000, 2005, 2010, and 2015. Chu, et al. [14] put forward ecological tension index (ETI), ecological occupancy index (EOI), and ecological economic coordination index (EECI) to evaluate ecological 
security of BTH region between 1995 and 2010. The results reveal that the ecological security situation in BTH region is serious. Additionally, some studies analysis the ecological sustainability of a typical province in China, such as Jilin [15], Jiangsu [16], and Anhui [17].

There are many studies that estimate and evaluate the ecological footprint in the city level. Wang, et al. [18], Yao, et al. [19] analyzed the spatial and temporal patterns of ecological footprint and ecological carrying capacity in Wuhan. Wang and Wang [20] constructed the Eco-City Practices framework, calculated and analyzed the ecological footprint of Xi'an from 1999 to 2014 by adding environmental pollution to the EF model. Li, et al. [21] combined ecological footprint with system dynamics software Stella to construct a predictable model of ecological sustainable development to study ecological sustainable development in Chengdu. Fan, et al. [22] took non-renewable resources and water resources into consideration, presented a modified ecological footprint accounting model to appraise the environmental impact of an industrial park-Hefei economic and technological development area. Zhen and $\mathrm{Du}$ [23] estimated the ecological footprint of food consumption in Guyuan City of Ningxia Hui Autonomous region by using ecological footprint models. Dai, et al. [24] modified the EF model by using component analysis and considering the main features of a historic district, then they constructed the ecological footprint model of historic districts in two dimensions: residents and tourists. As an example, the results for Nanluoguxiang in Beijing showed that the EF was substantially higher than the $\mathrm{EC}$, whereas the $\mathrm{EF}$ of tourists was higher than the EF of residents. Chen, et al. [25] evaluated the ecological carrying capacity of tourism industry in Zhoushan City from 2010 to 2014 by ecological footprint analysis. Chen [26] evaluated the ecological security of Qingjing area in Taiwan by using the energy ecological footprint model.

In recent years, the situation of ecological sustainable development in ecologically fragile areas and poor mountainous areas has received the attention of researchers. Tian [27] calculates the ecological footprint of Dabieshan Pilot Site in 2008, and the results show that there is greatly agricultural ecological deficit, and finally leads to the shortage of ecological supply capacity. Using the method of ecological footprint, Peng, et al. [28] evaluated the development potential of mountain cities in 12 counties of the Dali Bai Autonomous Prefecture in Yunnan province. Wang, et al. [29] adopted the conception of ecological deficit to find that Shenmu county was practicing unsustainable development. Bai, et al. [30] evaluated the sustainability of cropland utilization in a country in Loess Plateau region (Yuanzhou) during 1981-2009. Wang, et al. [31] calculated the ecological footprint of Ruyang county from 2004 to 2013.

In recent years, the ecological footprint model is also applied to project evaluation innovatively. Dang, et al. [32] analyzed the ecological-economic process of an ecological restoration program and its implications for land use and environmental policy in the Feimahe catchment in the Loess Hilly Region of China in 1998-2005 by combining the EF model and the energy synthesis method. Taking the South-North Water Transfer Middle Route Project as an example, Wei and Xia [33] calculated the losses of ecological immigrants and provided a more reasonable compensation amount based on the ecological footprint theory. Wang, et al. [34] tracked the change trajectories of rural household livelihoods and regional ecological footprints in four water source areas (Shiyan, Nanyang, Tai'an, and Jining) of the South-to-North Water Diversion Project in 2000-2014. Wang, et al. [35] assessed the positive and negative impacts of cascaded diversion small hydropower (SHP) on environment. With the raising in the number $(n>4)$ of diversion SHP stations, the difference between ecological loss footprint(ELF) and ecological supply footprint (ESF) increases remarkably, suggesting that the adverse impacts of cascaded diversion SHP accumulate in the study area. Hu, et al. [36] took Guyuan for instance and assessed the EFs of various biological resource products before and after the implementation of the Green for Grain Project (1998-2012). The results showed that the per capita EF and ecological deficit of Guyuan significantly decreased after the project. Zhen and Du [23] suggested that the Grain for Green program increased the biological capacity (BC) of forest and grassland, but it also decreased the $\mathrm{BC}$ of cultivated land. In addition, some literatures has investigated the new 
agricultural animal husbandry projects (such as the "hog-biogas-fish" system) [37], national nature reserves [38], the ecological footprint of food consumption of residents [39,40].

In addition, part of the study also discussed the impact of international trade on the ecological footprint in the context of globalization. Lazarus, et al. [41] illustrated that almost $35 \%$ of the carbon Footprint was embodied in international trade. Figge, et al. [42] conclude that the overall index of globalization significantly increases the Ecological Footprint of consumption, exports, and imports. Gao and Tian [43] used the ecological trade deficit to assess the pressure created by the export and import of resources and products.

Although the ecological footprint model has many advantages, it does not distinguish between the stock capital and the flow capital, therefore it cannot show the important role of the stable stock capital to maintain the balance of the ecosystem. Niccolucci, et al. [44] added footprint depth and footprint size based on traditional ecological footprint models to explain the depletion of natural resources and the use of flows at the national and global levels, respectively. So that the ecological footprint model can be developed from two-dimensional to three-dimensional (3D). Fang [45] thought that the 3D model becomes a temporal-spatial approach to better explain the difference between human demand for natural capital flows and stocks, enhanced comparability between either different regions or different generations, and is partly able to avoid excessively conservative estimates. Fang [45] analyzed ecological footprint in China from 1961 to 2006 by using a 3D ecological footprint model, and it is concluded that the footprint depth has almost tripled since 1978 when China entered an ecological deficit era, while the footprint size declined by $11.84 \%$. This presents a huge demand for compensating the lack of natural capital flows through depletion of stocks under the high human induced pressure. Peng, et al. [46] presented a multi-dimensional "ecology-equity-efficiency" framework based on the three-dimensional ecological footprint model to quantify the sustainability of natural capital utilization in Beijing.

\section{Study Area}

The object of this study is Hunan province $\left(108^{\circ} 47^{\prime} \sim 114^{\circ} 15^{\prime} \mathrm{E}, 24^{\circ} 38^{\prime} \sim 30^{\circ} 08^{\prime} \mathrm{N}\right)$. It is located in the central China, covering 13 prefecture-level cities and one autonomous prefecture (Figure 1). Most of the provincial boundaries are located in the south of Dongting Lake. The Xiangjiang River, the largest river in the province, runs through the north and south of the province. It covers about 21.1836 million hectares, accounting for about $2.2 \%$ of the total land area of the whole country; the permanent population is about 68.22 million. In 2015, its GDP was 2.90472 trillion Yuan (RMB), and the per capita GDP reached 42968 Yuan (RMB), which ranked ninth and sixteenth in China respectively [47,48].

Geographically speaking, Hunan province is located in the transition zone from Yungui Plateau to Jiangnan Hill and Nanling Mountain to Jianghan Plain. The whole province is surrounded by mountains on three sides of the east, west, and south. The central hills are undulating, and the northern lakes and plains are distributed, forming an asymmetric "horseshoe" terrain to the Northeast. The land resources in the territory are rich, the types of land are various, the surface of land is undulating and the geomorphologic type is mainly mountainous, the area of mountain (including highland area) accounts for $57.61 \%$ of the total land area of the whole province. Hunan has developed water systems, dense river networks, and wide lakes. The main rivers, Xiang, Zi, Yuan, Li (referred as "Sishui"), mostly for the south-north and southwest-northeast direction. Flowing from the surrounding mountains through the central basin and into the Dongting Lake to form a radial water system. Dongting Lake is the second largest fresh water lake in China, which accept "Sishui" and throughput the Yangtze River, and it is an important type of storage and discharge of lake in middle reaches of the Yangtze River. The territory is rich in animal and plant, mineral, tourism and other resources. It is famous for "hometown of fish and rice", "hometown of nonferrous metals", "hometown of non-metallic minerals" and "tourist resort". Rich land resources and its diversified distribution provide important material basis for the development and ecological construction of the province. 


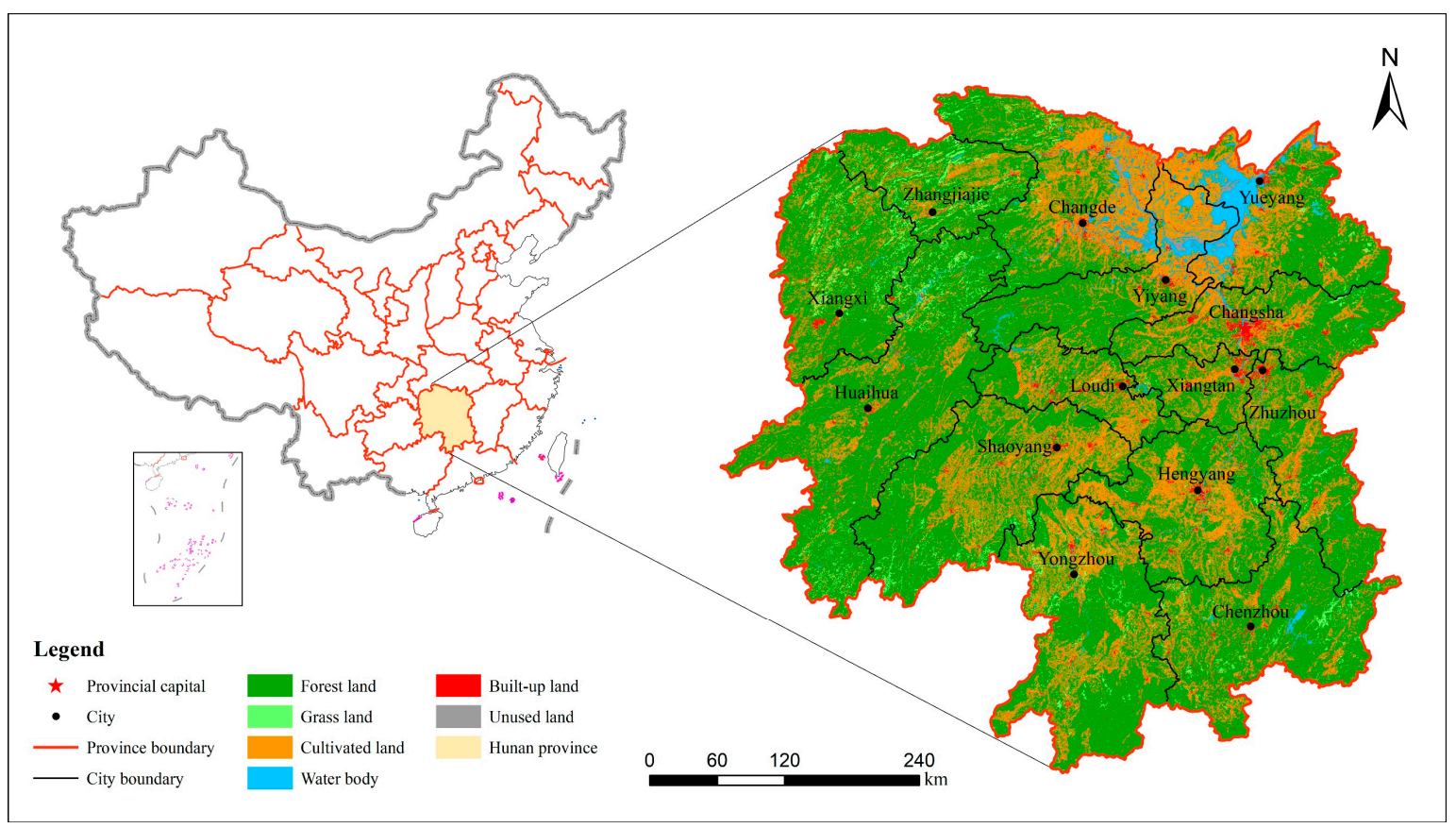

Figure 1. Location of the study area and land cover (2015).

In the field of ecological civilization construction, Hunan has been at the forefront of the country. In December 2007, Changsha-Zhuzhou-Xiangtan Urban Agglomeration in Hunan has been approved as a reform pilot area to build an "resource-saving and environment-friendly society", and it is expected to explore the new road of economic and social development coordinated with population, resources and environment. The green development index, published in December 2017, shows that the green development index of Hunan ranks eighth in the country. The "environmental quality index", "ecological protection index" and "growth quality index" of green development index rank among the top ten in China. Therefore, understanding about ecological sustainability of Hunan province is important for promoting of ecological civilization, economical development of resources, and environment-friendly society.

\section{Methods and Materials}

\subsection{Methods}

\subsubsection{Three-Dimensional Ecological Footprint Model}

The ecological footprint model is a method which tries to calculate the degree of human utilization of natural data and the function of life support services provided by nature to human beings. It calculates the required biologically productive land area of consumption of natural resources to maintain human survival and human waste, and compares it with the ecological carrying capacity of a given population area, which is to measure the condition of sustainable development of regional ecological environment and the degree of ecosystem security. According to the ecological footprint model, the material consumption of human activities needs the corresponding biologically productive land area to complete, and the biologically productive land area can always be related to a certain surface of the earth. Therefore, the land area based on the earth's surface can be used as a basic index to measure ecological capital, which is also the core idea of ecological footprint theory. Due to the difficulty of data collection, biologically productive land can be divided into six categories according to the difference of biological productivity and biomass species suitable for growth, that is, cropland, forestland, grazing land, fishing grounds, carbon uptake land (for the absorption of anthropogenic carbon dioxide emissions) and built-up land. In an ecosystem, all material cycles flow and transform in 
the form of energy. Therefore, in order to make the results comparable, Wackernagel, et al. [49] using the relative productive capacity of land to adjust the weight of the above six biological production areas with different ecological productivity, this weight is called "equivalence factor". The equivalence factor of cropland, forestland, grazing land, fishing ground, carbon dioxide and built-up land are 2.82, $1.14,0.54,0.22,1.14$ and 2.82 , respectively. Therefore, the specific empirical formula for ecological footprint (EF) is as follows [45]:

$$
E F=N \cdot e f=N \sum_{i=1}^{6}\left(r_{i} c_{i j} / p_{i j}^{n}\right)
$$

where $E F$ and ef stand for the total ecological footprint and the per capita ecological footprint respectively; $N$ is the population; $r_{i}$ is the equivalence factor corresponds to the $i$ th type of land; $c_{i j}$ is the per capita production of $j$ item product on the $i$ th type of land, and $p_{i j}^{n}$ is the national average yield for product $j$ on the $i$ th type of land.

It is worth noting that $p_{i j}^{n}$ in the Formula (1) is the national average productivity rather than the global average productivity, that is, it measures the average productivity of all biologically productive land within a country, including land and water. This is because the object of this study is Hunan province in central China. Based on the "National Hectare" model, the calculated results are more consistent with the actual situation of this study.

According to Equation (1), the ecological footprint is a function of population and per capita material consumption, and the ecological footprint is the sum of the biological production area (the demand for land) of each consumer commodity. Comparing with the area of biological production (land supply) provided by the research scope, it can provide a quantitative basis for judging whether the production and consumption activities in this area are within the carrying capacity of the ecosystem. For the latter, the biocapacity indicator is used to measure it in the literature [14]. The calculation formula of biocapacity indicator is as follows:

$$
B C=N \cdot b c=N \cdot(1-12 \%) \sum_{i=1}^{6}\left(r_{i} w_{i} a_{i}\right)
$$

where $B C$ and $b c$ stand for the total biocapacity and the per capita biocapacity, respectively; $w_{i}$ is the yield factor corresponds to the $i$ th type of land and it describes the difference between the productivity of a certain biologically productive land in a given region and the average productivity of the national land type [50]; $a_{i}$ is the per capital biologically productive area of $i$ th type of land; The definition of $N$ and $r_{i}$ is the same as Formula (1).

Different types of land have different yield factors. In this paper, the yield factors of different land types in China are calculated according to the ecological footprint account of the natural foundation of the world. The yield factor of cropland, forestland, grazing land, fishing ground, carbon dioxide and built-up land are $1.66,0.91,0.19,1,0$, and 1.66 respectively. In addition, $88 \%(=1-12 \%)$ of the Formula (2) is derived from the use of all different lands for the provision of resources or the absorption of $\mathrm{CO}_{2}$ for human beings, and a certain amount of land must be reserved for biodiversity conservation. According to the World Commission on Environment and Development (WCED), this ratio is set to $12 \%$, that is, only $88 \%$ of the land is used to provide resources for human being.

The difference between Formula (2) and Formula (1) is often used to measure the ecological security of the region. If the difference is greater than 0 , it means the ecological surplus (ES), which indicates that the ecological capacity of the evaluation region can support its human load, the income flow of natural capital in the region is larger than the demand flow of population consumption, and the total amount of regional natural capital may be increased. The ecological capacity of the region is expected to expand and the consumption pattern of the region is relatively sustainable. On the contrary, it is ecological deficit (ED), which indicates that the human load of the evaluation area exceeds its ecological capacity. To meet the consumption needs of its population under the current living 
standards, the region either imports resources from outside of the region to balance the ecological footprint, or consumes natural capital to make up for the lack of income supply flow. Both of these cases indicate that the regional development model is unsustainable.

Although the classical two-dimensional ecological footprint model recognizes the importance of natural capital in sustainable development, it does not distinguish between stock capital and flow capital. It cannot show the important role of stock capital remaining unchanged to maintain ecosystem balance. Niccolucci, Galli, Reed, Neri, Wackernagel and Bastianoni [44] extended the original two-dimensional model to a three-dimensional model by introducing the footprint depth and footprint size, which evaluates the ecological sustainability according to whether the stock capital is used or not rather than the absolute values of ecological footprint and ecological deficit.

Ecological footprint depth $\left(E F_{\text {depth }}\right)$ refers to the extent of natural capital stocks are consumed in order to meet human needs. The formula is as follows:

$$
E F_{\text {depth }}=1+\frac{E D}{B C}=1+\frac{\max (E F-B C, 0)}{B C}
$$

For Formula (3), $E F_{\text {depth }}=1$ if $E F \leq B C$; otherwise $E F_{\text {depth }} \geq 1$. This conclusion implies that the higher value of $E F_{\text {depth }}$ corresponding to the higher consumption of natural capital, thereby disadvantage to the sustainable development.

Additionally, it can be inferred that $E F_{\text {size }}=E F / E F_{\text {depth }}$ [50], which is the amount of natural capital flow occupied each year to meet the needs of human production and consumption. Because the consumption of capital flow could not reduce the natural capital, so $0 \leq E F_{\text {size }} \leq B C$. Compared with the two-dimensional model, the ecological footprint size in the three-dimensional model can represent the equity differences of resource consumption and ecological services between different regions in the same period. The ecological footprint depth in the three-dimensional model can represent the equity difference of resource consumption and ecological service between different periods in the same region, so that the comparability of ecological footprint in different regions and different periods can be enhanced.

\subsubsection{Indicator System for Sustainability Based on Ecological Footprint}

Because the simple ecological surplus or deficit cannot accurately reflect regional ecological sustainability, this paper introduced another two indices to evaluate the regional ecological sustainability. Firstly, we adopt the Shannon-Weaver formula to calculate the ecological footprint diversity index [51]. In ecology, the Shannon-Weaver diversity index is often used to estimate community diversity in ecosystem:

$$
H_{e f}=-\sum_{i=1}^{6}\left(P_{i} \times \ln P_{i}\right)
$$

where $H_{e f}$ is the ecological footprint diversity index and $P_{i}$ is the proportion of the $i$-th land type in the total ecological footprint. From the above formula we can see that the ecological diversity index is composed by two parts: firstly, the proportion of six types of biologically productive land area represents the degree of equity. Secondly, the total area of biological production of all types of land represents the degree of affluence. The formula is not monotonous; when the proportion of land use of all types is the same (i.e., value $=1 / 6), H_{e f}$ has the maximum value. The more balanced the distribution of biologically productive land area, the better the stability of different eco-economic system.

Furthermore, we introduced the development capacity index based on the Ulanowicz method, which reflects the developmental status of the ecological economic system. The formula is as follow [51]:

$$
D_{e f}=e f \times H_{e f}
$$


where $D_{e f}$ is the development capacity index and ef is the per capita ecological footprint. According to Equation (5), improving the ecological footprint diversity is an efficient way to increase the development capacity.

\subsubsection{Ecological Efficiency}

The ecological footprint measures the demand for natural resources by economic activities. Similar to the GDP per unit of energy consumption, this section uses the GDP per unit of ecological footprint to measure ecological efficiency (EE), that is:

$$
E E=G D P / E F
$$

Furthermore, we adopted the concept of distance function to reveal the drive forces of ecological efficiency change. Considering produce output $(y)$ can be produced by input $(x)$, which can be denoted as $T^{t}=\left\{\left(x^{t}, y^{t}\right) \mid x^{t}\right.$ can produce $\left.y^{t}\right\}$. Furthermore, the output distance function is defined as [52]:

$$
D_{\mathrm{o}}^{t}\left(x^{t}, y^{t}\right)=\min \left\{\theta \mid\left(x^{t}, y^{t} / \theta\right) \in T^{t}\right\}
$$

The Formula (7) shows that the output distance function refers to the reciprocal of the multiple of the maximum expansion of output $y$ given input $x$. Accordingly, the maximum output under the constraint of $T^{t}$ is $y_{\max }^{t}\left(x^{t} ; T^{t}\right)=y^{t} / D_{o}^{t}\left(x^{t}, y^{t}\right)$.

Furthermore, we derive the decomposition formula of ecological efficiency change. We incorporate ecological footprint into the production function as a special input factor. That is $\left(x^{t}, y^{t}\right)=\left(K^{t}, L^{t}, E F^{t}, Y^{t}\right) . Y$ is the output and measured by GDP; $K, L$ is the capital stock and labor input, respectively; EF is the total ecological footprint calculated by Formula (1). Data Envelopment Analysis (DEA) was proposed by Charnes and Cooper in 1978. It is a method to evaluate the efficiency of multiple decision units with multiple inputs and outputs. One of the methods is the Malmquist index, which is an effective method to measure the efficiency of multiple inputs and outputs. In recent years, it has been widely used in academia. Using the constant scale return assumption and Malmquist-DEA method, we can get:

$$
\begin{gathered}
\frac{E E_{t}}{E E_{t-1}}=\frac{Y_{t} / E F_{t}}{Y_{t-1} / E F_{t-1}}=\frac{D_{0}^{t}\left(K^{t}, L^{t}, E F^{t}, Y^{t}\right)}{D_{0}^{t-1}\left(K^{t-1}, L^{t-1}, E F^{t-1}, Y^{t-1}\right)} \times \\
{\left[\frac{D_{0}^{t-1}\left(K^{t}, L^{t}, E F^{t}, Y^{t}\right)}{D_{0}^{t}\left(K^{t}, L^{t}, E F^{t}, Y^{t}\right)} \times \frac{D_{0}^{t-1}\left(K^{t-1}, L^{t-1}, E F^{t-1}, Y^{t-1}\right)}{D_{0}^{t}\left(K^{t-1}, L^{t-1}, E F^{t-1}, Y^{t-1}\right)}\right]^{\frac{1}{2}} \times} \\
{\left[\frac{y_{\max }^{t}\left(k^{t}, l^{t} ; t^{t-1}\right)}{y_{\max }^{t-1}\left(k^{t-1}, l^{t-1} ; \tau^{t-1}\right)} \times \frac{y_{\max }^{t}\left(k^{t}, l^{t} ; \tau^{t}\right)}{y_{\max }^{t-1}\left(k^{t-1}, l^{t-1} ; \tau^{t}\right)}\right]^{\frac{1}{2}}} \\
=E F F C H \times T E C H \times I N P S U B
\end{gathered}
$$

where $\frac{E E_{t}}{E E_{t-1}}$ refers to the ecological efficiency change, $k=K / E F ; l=L / E F ; y=Y / E F ; \tau^{t}$ is the frontier of $(k, l, y)$ in t period, $D_{o}^{t}(\cdot)$ and $D_{o}^{t-1}(\cdot)$ refers to a distance function with reference to the technical level of the $t$ period and the $t-1$ period.

The Formula (8) shows that the ecological efficiency change can be decomposed into the technical efficiency change $(\mathrm{EFFCH})$, technical progress $(\mathrm{TECH})$ and the substitution effect of input factors (INPSUB). The product of EFFCH and TECH is the change of total factor productivity (TFPCH). The change of factor substitution is the change of capital footprint ratio and labor footprint ratio; factor substitution growth means that capital footprint ratio and labor footprint ratio increase on average, that is, ecological capital is replaced by other factors. With the improvement of economic development level and the strengthening of people's awareness of environmental protection, the relative price of ecological capital will be higher and higher, so it tends to be replaced by other elements. 
Generally speaking, the reasons of factor substitution are the industrial structure change and the change of factor relative price, etc. If the industrial structure tends to be resource-intensive, the ecological efficiency tends to decline; on the contrary, it tends to rise. The change of factors relative price not only affects the factor substitution by affecting industrial structure, but also directly affects the substitution of elements [53]. For example, the cheaper resources relative to labour prices would lead to more resources being used in economic activities (replacing labour with resources), which would have a negative impact on the improvement of ecological efficiency.

\subsection{Materials}

The calculation of ecological footprint requires detailed biological resources consumption and energy consumption. The consumption of biological resources is expressed by the crop yield of six types of biologically productive land area (Table 1).

Table 1. Biological products and energy sources in Hunan related to the biologically productive land categories.

\begin{tabular}{cl}
\hline Land Categories & Items of Biological Products and Energy Sources in Hunan \\
\hline Arable land & $\begin{array}{l}\text { Grains, rice, wheat, corn, other food crops; beans, potatoes, peanuts, rapeseed, sesame, } \\
\text { other oils, cotton, hemp, tobacco, medicinal herbs, vegetables, fruit melons, pork, } \\
\text { poultry meat, eggs }\end{array}$ \\
\hline Grazing land & Beef and mutton, other meat, wool, milk, rabbit \\
\hline Forest & $\begin{array}{l}\text { Citrus, peach, pear, other fruits, tea, mulberry, lacquer, oil seed, camellia seed, } \\
\text { turpentine, dried bamboo shoot, chestnut, wood, bamboo wood }\end{array}$ \\
\hline Water bodies & Fish, crabs, shellfish and other aquatic products \\
\hline $\begin{array}{c}\text { Carbon uptake land } \\
\text { (Carbon footprint) }\end{array}$ & $\begin{array}{l}\text { Consumption of raw coal, coke, crude oil, gasoline, kerosene, diesel oil, fuel oil, } \\
\text { liquefied petroleum gas, electricity }\end{array}$ \\
\hline Built-up area & Hydroelectricity \\
\hline
\end{tabular}

Arable land is used for the cultivation of crops, and it provides a large number of agricultural products. Most of the arable land in Hunan is used to grow grain crops, such as cereals, corn and other staple foods, as well as beans, potato and other supplementary food. Also, a large part of the arable land is used to grow cash crops, such as peanuts, rapeseed, cotton and tobacco leaves. In Hunan, pork and poultry are mainly processed by grain or crops, so the biological production land of pork and poultry meat is classified as cultivated land and the other is grassland. In this paper, the meat except pork and poultry and its related consumption (beef and mutton, other meat) are grazing demand land. Forest mainly provides fruit, wood, tea, camellia seed and other cash crops. Hunan is located inland, thus we take the freshwater fishing and aquaculture production to count the water area and its output.

Carbon uptake land is used to account for the amount of land needed to absorb greenhouse emissions from human activities. The greenhouse emissions from fossil fuel consumption, whether it comes from local production or import, need to be absorbed by local forests. Therefore, the calculation of the ecological footprint of fossil energy accounts in this paper is based on consumption, that is, using the fossil energy consumption data instead of producing data to calculate the corresponding ecological footprint (it is also known as carbon dioxide footprint or carbon footprint). Built-up area includes residential land, water conservancy, transportation, industrial and mining land, because most of the built-up area is occupied by arable land, so the yield factor and equilibrium factor of built-up area are the same as arable land. 


\section{Results and Discussion}

\subsection{Temporal and Spatial Variations in the Ecological Footprints in Hunan}

Figure 2 shows the change trend of the absolute amount of each component of ecological footprint in Hunan province. Overall, the total ecological footprint of Hunan shows an increased trend, and its increased from $6559.637 \times 10^{4} \mathrm{NHA}$ (national hectare) in 2005 to $7187.976 \times 10^{4} \mathrm{NHA}$ in 2014, and then decreased to $6770.053 \times 10^{4} \mathrm{NHA}$ in 2015. Accordingly, its ecological footprint per capita increased from 0.952 NHA in 2005 to 1.058 NHA in 2014, and then 0.988 NHA in 2015.

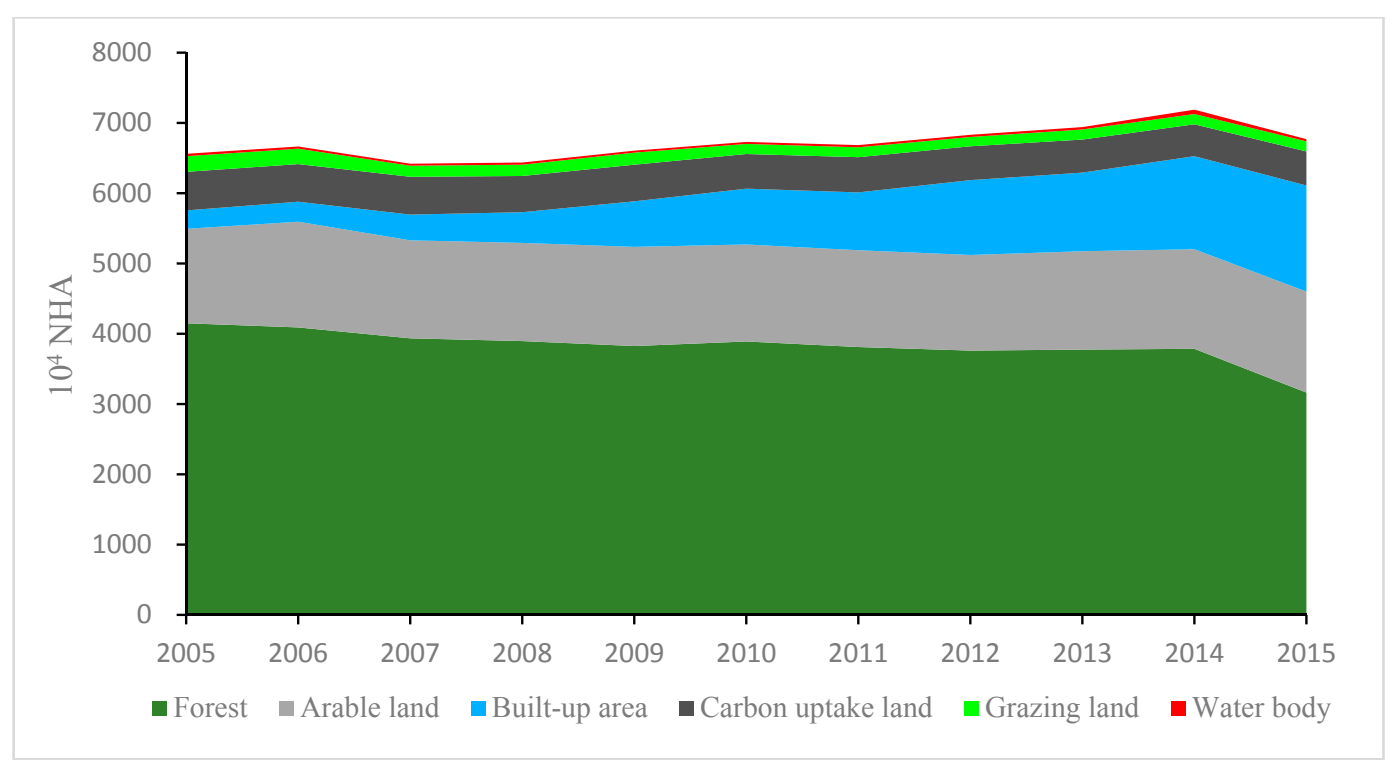

Figure 2. Composition and dynamic change of Ecological footprint in Hunan (tens of thousands NHA).

As for components of ecological footprint, forest is the main contribution source of Hunan's ecological footprint, and its annual contribution rate is $57.1 \%$, but it decreases in recent years; especially in 2014-2015, the ecological footprint of forest decreased by $16.4 \%$ or from $3786.92 \times 10^{4} \mathrm{NHA}$ to $3164.86 \times 10^{4}$ NHA. In addition, the other two main sources of ecological footprint are arable land and build-up land. The ecological footprint of arable land accounts for about $20 \%$ of the total ecological footprint, and its amount is maintained at about $1400 \times 10^{4} \mathrm{NHA}$. During the sample period, the ecological footprint of build-up land increased significantly, increasing from $263.47 \times 10^{4} \mathrm{NHA}$ in 2005 to $1511.73 \times 10^{4} \mathrm{NHA}$ in 2015 , and its proportion also increased from $4.0 \%$ in 2005 to $22.3 \%$ in 2015.

All cities in Shandong Province featured varying degrees of ecological deficits, and ecological development was unsustainable in 2010-2015 [54]. Because Shandong is the main grain-producing area in China, and the energy footprint indicates that mineral resource consumption occupies a larger proportion of capital stock consumption [55]. The ecological footprint assessment of a typical ecologically sensitive area in the southern Qin Ling piedmont of Shaanxi indicated that the per capita biological capacity remained stable at 2.100 ha/cap and that the per capita ecological footprint increased, with fluctuations between 1.359 ha/cap and 2.239 ha/cap. The main factors driving the ecological footprint size are commonly used arable land, the per capita disposable income of urban residents, and the primary industry output value [50]. Six cities in Poyang Lake basin of Jiangxi Province have low efficiency of ecological energy utilization, low level of overall productivity and low scientific and technological content of economic growth, which are the main reasons leading to the increase of ecological footprint of these cities year by year [7]. Different from the studies about other provinces in China, the ecological footprint of carbon uptake land in Hunan is relatively small and the trend is decreasing slowly. In recent years, it has fluctuated around $503 \times 10^{4} \mathrm{NHA}$. Here 
are two reasons: firstly, the carbon dioxide emissions of Hunan only accounts for about $3 \%$ of China, indicating that the demand for carbon uptake land in Hunan is relatively small compared with the national average demand for carbon uptake land. Therefore, the absolute ecological footprint of carbon uptake land calculated based on the Formula (1) is relatively small. Secondly, Hunan actively promotes low-carbon development. For example, as an energy-intensive sectors, the industrial added value of Hunan increased by 1.76 times in 2011-2015, but the absolute amount of industrial comprehensive energy consumption decreased by 684.3 ten thousand tons of standard coal, as a result, energy intensity of Hunan's industry sector decreased by $46.2 \%$ in 2011-2015. This is mainly due to the promotion of green and low-carbon industrial development in Hunan under the green development concept. In recent years, industrial growth has been "decoupled" from $\mathrm{CO}_{2}$ emissions, with rapid industrial development and a decrease in total industrial energy consumption. However, the total amount of carbon emissions has not significantly increased (or even decreased), and the energy intensity, one of the major contributors to industrial carbon emissions, has also decreased.

In addition, Figure 2 shows that the ecological footprint of grazing land and water bodies is relatively small. The ecological footprint of grazing land decreased overall, but increased in 2007-2008 and 2012, and finally stabilized around $144 \times 10^{4} \mathrm{NHA}$, and the ecological footprint of water bodies basically stabilized at $30 \times 10^{4} \mathrm{NHA}$. However, there was a sudden increase in 2014 , which may be related to the rapid increase in the output of aquatic products in Changsha.

Furthermore, we discuss the spatial distribution of ecological footprint in Hunan province based on the per capita ecological footprint. Figure 3 shows that the distribution pattern of the per capita ecological footprint in Hunan province. The high value areas of per capita ecological footprint are mainly distributed in the west and north of Hunan, while the low value areas are mainly in Xiangtan and Loudi of the central Hunan. Among them, the per capita ecological footprint of Huaihua is obviously higher than that of other cities, whose annual average is 1.61 NHA, followed by Yongzhou in southwest of Hunan, 1.34 NHA. The lowest per capita ecological footprint is Xiangtan with an annual average of $0.42 \mathrm{NHA}$, and the secondary lower is Loudi, $0.49 \mathrm{NHA}$. According to the spatial distribution difference, the annual average of per capita ecological footprint in Huaihua is 3.83 times that of Xiangtan.
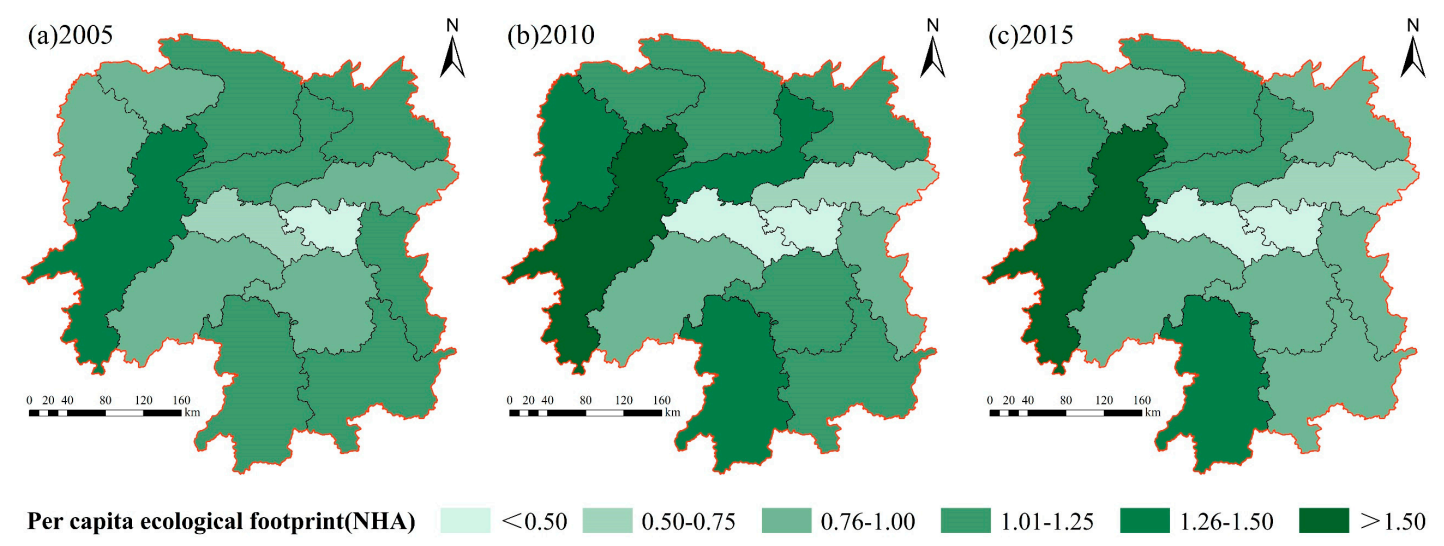

Figure 3. Per capita ecological footprint of Hunan Province (NHA per person).

\subsection{Evolution of Ecological Sustainability in Hunan}

\subsubsection{Temporal and Spatial Variations in Ecological Capacity in Hunan}

The ecological carrying capacity of Hunan can be obtained according to the Formula (2). The results show that the ecological carrying capacity of Hunan Province remains basically stable during the sample period (Figure A1 in the Appendix A). Among them, the ecological carrying capacity of arable land is the highest, with the total ecological carrying capacity is about $1859.6 \times 10^{4} \mathrm{NHA}$, which accounts for $49.3 \%$ of the total ecological carrying capacity in Hunan. Followed by forest 
and build-up land, and the total ecological carrying capacity of forest land is basically stable at $1183.8 \times 10^{4} \mathrm{NHA}$, which accounting for about $31.4 \%$. During the sample period, the ecological carrying capacity of build-up land increased from $693.37 \times 10^{4} \mathrm{NHA}$ to $759.96 \times 10^{4} \mathrm{NHA}$, in 2015 . In addition, the ecological carrying capacity of grazing land and water body was very small, accounting for only about $0.1 \%$ of the total ecological carrying capacity in Hunan. The per capita ecological carrying capacity of Hunan increased from 0.585 NHA in 2005 to the maximum (0.611 NHA) in 2010, and then decreased to 0.598 NHA in 2015.

Furthermore, the per capita ecological carrying capacity of Hunan also presents a distribution pattern of "high in surround, low in the central" (Figure 2). The high value areas of per capita ecological carrying capacity are mainly distributed in Zhangjiajie and Xiangxi prefectures of western Hunan, and the annual mean value is $0.9 \mathrm{NHA}$ and $0.85 \mathrm{NHA}$, respectively, and the lowest value of per capita ecological carrying capacity is Changsha whose annual average is 0.38 NHA.

Figure 4 shows that the per capita ecological footprint of Hunan Province was always larger than the per capita ecological carrying capacity in 2005-2015, which means that Hunan Province has been in a state of ecological deficit, and natural capital flows are not sufficient to support the expanding consumption demand, so it need to consume the stock of ecological capital to maintain our own development. The larger the ecological deficit (the difference between the ecological footprint and the ecological carrying capacity), the greater the ecological pressure. Such a development model is unsustainable for Hunan Province, it needs to improve the mode of economic development to ease the pressure on the ecological environment. Regional population size and the amount of energy consumed should be rationally controlled, and optimize the energy consumption structure is the improvements in the capacity for regional sustainable development of Shandong Province [55].

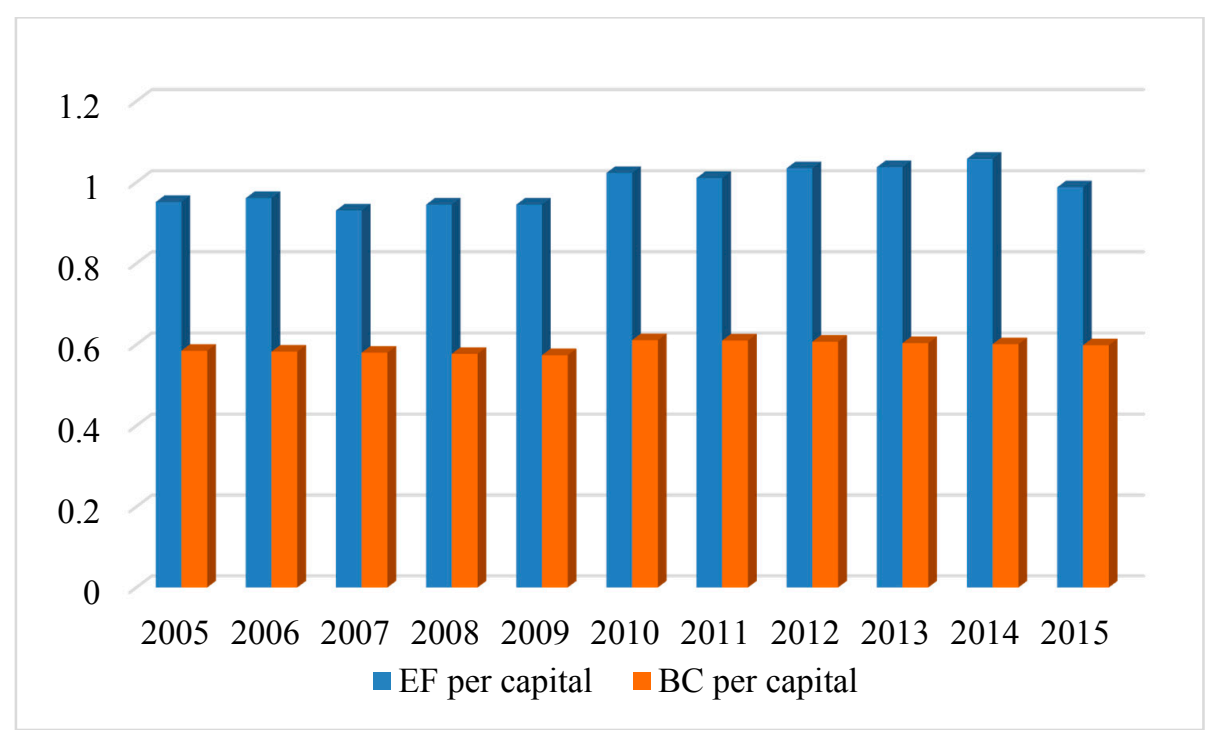

Figure 4. Per capita ecological footprint and per capita ecological carrying capacity of Hunan province (NHA/person).

\subsubsection{Analysis of Ecological Footprint Depth and Ecological Footprint Size}

Figure 5 shows that the per capita ecological footprint of Hunan Province fluctuated slightly at around $0.58 \mathrm{NHA} /$ person in 2005-2009; it rapidly increased to a maximum (0.609 NHA/person) in history in 2010, and the actual share of natural capital flows also reached its largest level. The per capita ecological footprint gradually decreased to about 0.60 NHA/person in 2010-2015. Correspondingly, the ecological footprint depth fluctuated between 2005 and 2014, and the ecological footprint depth declined rapidly to about 1.66 in 2015 due to the significant reduction of the ecological deficit in 2014-2015. In addition, during the sample period, the ecological footprint depth of Hunan has always been greater than 1, which also supports the conclusion that Hunan is always in ecological deficit. 


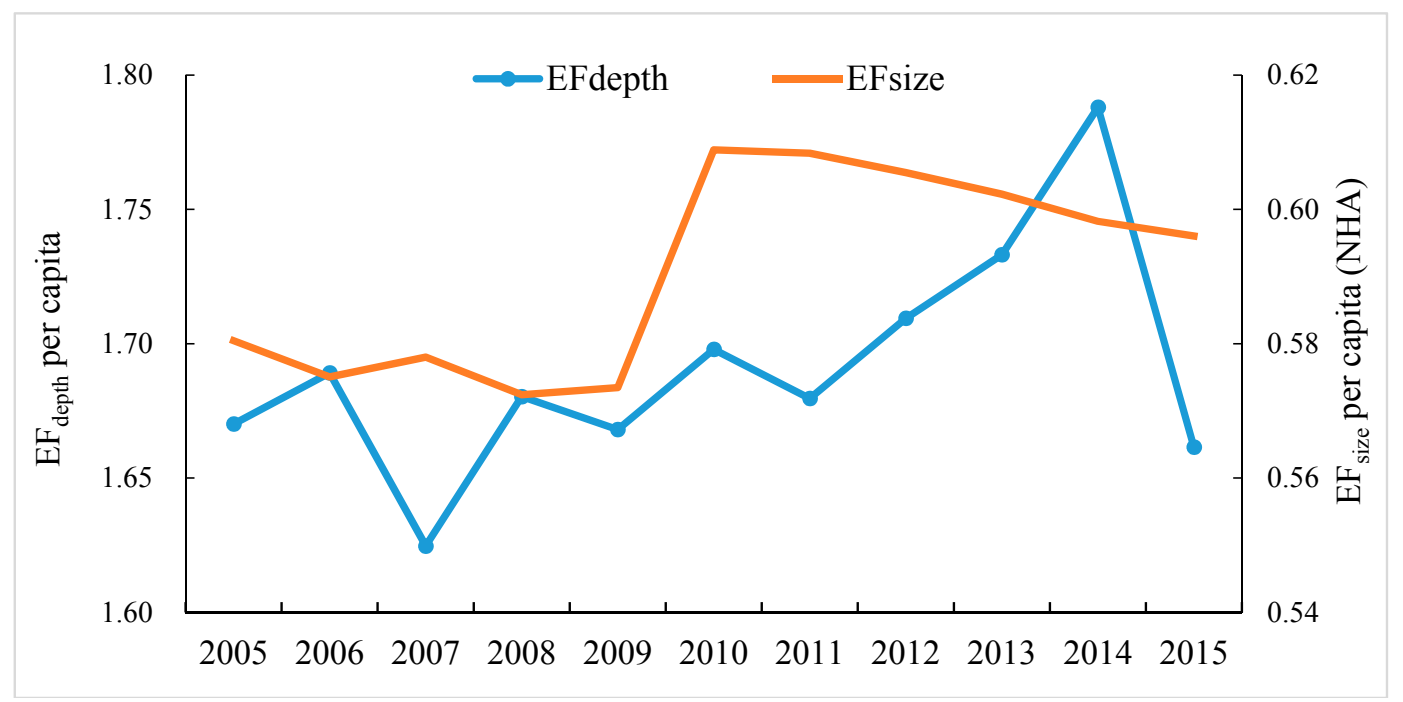

Figure 5. Changes of ecological footprint depth and size in Hunan Province from 2005 to 2015.

From the view of spatial distribution (Figure 6), the ecological footprint depth of different cities (states) is different. The high value areas of the per capita footprint depth are mainly distributed in Yiyang, Yongzhou, and Hengyang, with the annual mean values of 2.44, 2.04, and 2.02, respectively. In addition, the per capita footprint depth of Xiangtan, Zhangjiajie, and Loudi is close to 1 . The ecological footprint size of cities (prefectures) presents a distribution pattern of "higher in central and lower in surround". The high value areas of the per capita footprint size are mainly in the western Hunan region, among which, the annual average value of Zhangjiajie is the highest (0.89 NHA). The low value area of per capita footprint is mainly in Changsha, Xiangtan, and Loudi of central Hunan.

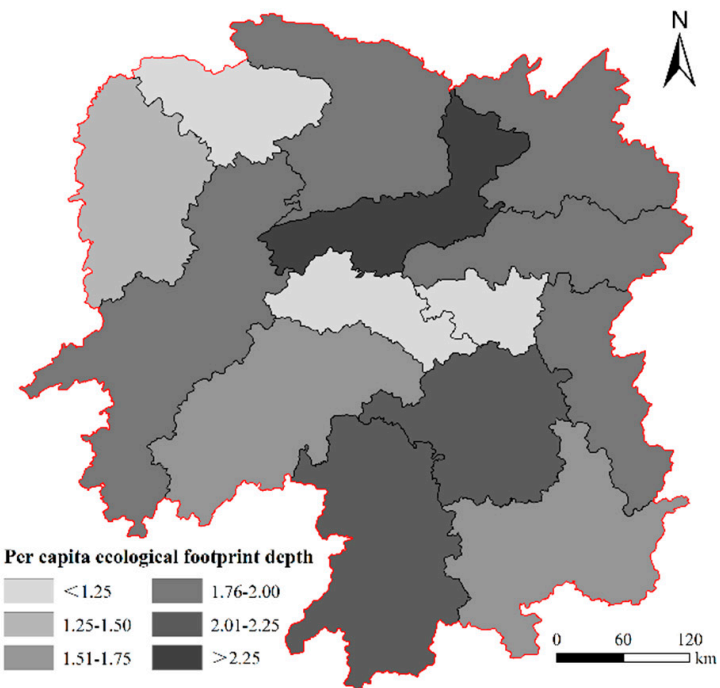

(a)

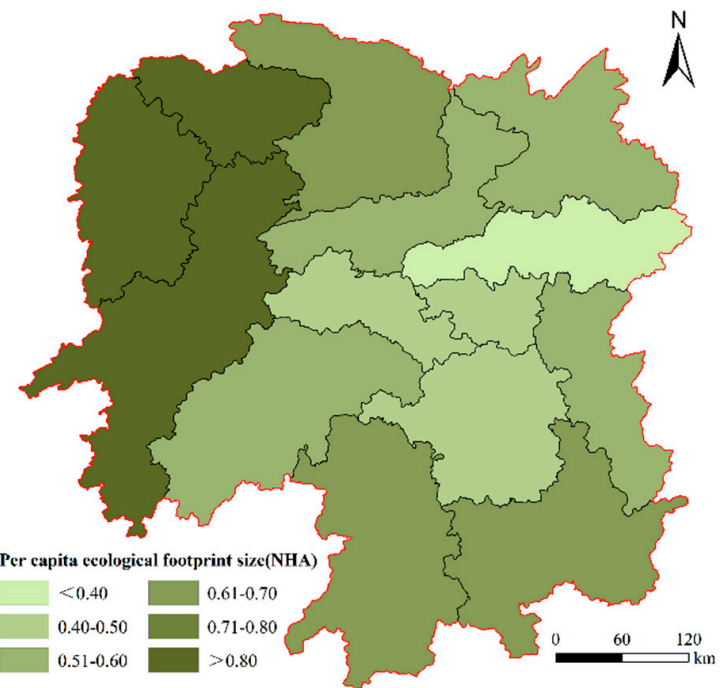

(b)

Figure 6. Annual mean values of per capita ecological footprint depth and size in Hunan Province from 2005 to 2015. (a) Annual mean values of per capita ecological footprint depth. (b)Annual mean values of per capita ecological footprint size

\subsubsection{Analysis of Ecological Footprint Diversity Index and Development Capacity Index}

To assess regional ecological sustainability, we calculated the ecological footprint diversity index and the development capacity index. The results are shown in Tables 2 and 3. 
Table 2. Ecological Footprint Diversity Index of Hunan in 2005-2015.

\begin{tabular}{|c|c|c|c|c|c|c|c|c|c|c|c|c|c|c|}
\hline \multirow{2}{*}{ Year } & \multicolumn{14}{|c|}{ Ecological Footprint Diversity Index } \\
\hline & Changsha & Zhuzhou & Xiangtan & Hengyang & Shaoyang & Yueyang & Changde & Zhangjiajie & Yiyang & Chenzhou & Yongzhou & Huaihua & Loudi & Xiangxi \\
\hline 2005 & 1.23 & 0.97 & 1.17 & 1.09 & 1.02 & 1.02 & 1.09 & 1.07 & 1.02 & 1.07 & 0.95 & 0.90 & 1.13 & 0.76 \\
\hline 2006 & 1.22 & 0.95 & 1.15 & 1.06 & 1.04 & 1.04 & 1.07 & 1.08 & 1.21 & 1.03 & 1.07 & 0.96 & 1.21 & 0.75 \\
\hline 2007 & 1.18 & 1.03 & 1.15 & 1.06 & 1.07 & 1.03 & 1.10 & 1.05 & 1.18 & 1.05 & 0.96 & 0.98 & 1.24 & 0.74 \\
\hline 2008 & 1.20 & 0.85 & 1.11 & 1.12 & 1.15 & 1.10 & 1.11 & 1.11 & 0.96 & 1.10 & 1.12 & 1.04 & 1.09 & 0.73 \\
\hline 2009 & 1.21 & 1.36 & 1.15 & 1.14 & 1.18 & 1.05 & 1.16 & 1.15 & 0.94 & 1.13 & 1.18 & 1.02 & 1.33 & 0.76 \\
\hline 2010 & 1.24 & 1.34 & 1.13 & 1.03 & 1.19 & 1.06 & 1.14 & 1.10 & 0.95 & 1.20 & 1.15 & 0.97 & 1.32 & 0.74 \\
\hline 2011 & 1.25 & 1.25 & 1.16 & 1.04 & 1.16 & 1.14 & 1.10 & 1.06 & 1.01 & 1.26 & 1.14 & 1.01 & 1.31 & 0.71 \\
\hline 2012 & 1.31 & 1.23 & 1.16 & 1.11 & 1.18 & 1.09 & 1.12 & 1.07 & 0.97 & 1.25 & 1.16 & 0.88 & 1.32 & 0.72 \\
\hline 2013 & 1.28 & 1.29 & 1.16 & 1.15 & 1.24 & 1.12 & 1.08 & 1.12 & 0.94 & 1.27 & 1.16 & 0.84 & 1.35 & 0.77 \\
\hline 2014 & 1.45 & 1.21 & 1.15 & 1.18 & 1.28 & 1.11 & 1.22 & 1.16 & 1.04 & 1.23 & 1.18 & 0.60 & 1.25 & 0.76 \\
\hline 2015 & 1.37 & 1.39 & 1.21 & 1.16 & 1.38 & 0.67 & 1.34 & 1.20 & 1.26 & 1.32 & 1.25 & 0.50 & 1.40 & 0.89 \\
\hline mean & 1.27 & 1.17 & 1.16 & 1.10 & 1.17 & 1.04 & 1.14 & 1.11 & 1.04 & 1.17 & 1.12 & 0.88 & 1.27 & 0.76 \\
\hline
\end{tabular}

Table 3. Eco-economy Development Capacity Index of Hunan in 2005-2015.

\begin{tabular}{|c|c|c|c|c|c|c|c|c|c|c|c|c|c|c|}
\hline \multirow{2}{*}{ Year } & \multicolumn{14}{|c|}{ Development Capacity Index (NHA) } \\
\hline & Changsha & Zhuzhou & Xiangtan & Hengyang & Shaoyang & Yueyang & Changde & Zhangjiajie & Yiyang & Chenzhou & Yongzhou & Huaihua & Loudi & Xiangxi \\
\hline 2005 & 0.96 & 0.97 & 0.56 & 0.93 & 0.91 & 1.15 & 1.22 & 0.87 & 1.05 & 1.29 & 1.13 & 1.23 & 0.58 & 0.72 \\
\hline 2006 & 0.95 & 1.00 & 0.51 & 0.93 & 0.93 & 1.17 & 1.24 & 0.83 & 1.01 & 1.27 & 1.29 & 1.42 & 0.69 & 0.79 \\
\hline 2007 & 0.93 & 1.01 & 0.50 & 0.89 & 0.85 & 1.05 & 1.14 & 0.88 & 0.91 & 1.28 & 1.25 & 1.34 & 0.60 & 0.85 \\
\hline 2008 & 0.92 & 1.29 & 0.44 & 0.85 & 0.86 & 0.99 & 1.17 & 0.90 & 1.07 & 1.11 & 1.17 & 1.36 & 0.70 & 0.84 \\
\hline 2009 & 0.97 & 1.07 & 0.47 & 0.97 & 0.93 & 1.11 & 1.24 & 1.01 & 1.28 & 1.32 & 1.27 & 1.49 & 0.55 & 0.85 \\
\hline 2010 & 0.88 & 1.09 & 0.47 & 1.06 & 0.95 & 1.08 & 1.29 & 1.17 & 1.39 & 1.36 & 1.59 & 1.60 & 0.58 & 0.95 \\
\hline 2011 & 0.84 & 1.04 & 0.49 & 1.12 & 0.95 & 1.08 & 1.32 & 1.20 & 1.38 & 1.42 & 1.66 & 1.51 & 0.58 & 0.84 \\
\hline 2012 & 0.78 & 1.08 & 0.48 & 1.00 & 0.96 & 0.93 & 1.36 & 1.16 & 1.60 & 1.57 & 1.72 & 1.52 & 0.61 & 0.83 \\
\hline 2013 & 0.90 & 1.14 & 0.50 & 0.98 & 1.05 & 0.92 & 1.31 & 1.20 & 1.62 & 1.56 & 1.78 & 1.44 & 0.58 & 0.82 \\
\hline 2014 & 1.10 & 1.27 & 0.47 & 0.95 & 1.17 & 0.94 & 1.45 & 1.07 & 1.77 & 1.27 & 1.84 & 1.23 & 0.70 & 0.79 \\
\hline 2015 & 0.96 & 1.27 & 0.50 & 1.01 & 1.19 & 0.51 & 1.51 & 1.11 & 1.57 & 1.28 & 1.84 & 1.04 & 0.60 & 0.94 \\
\hline mean & 0.93 & 1.11 & 0.49 & 0.97 & 0.98 & 0.99 & 1.30 & 1.04 & 1.33 & 1.34 & 1.50 & 1.38 & 0.61 & 0.84 \\
\hline
\end{tabular}


Table 2 shows that, except Xiangxi and Huaihua, the ecological footprint diversity index of all prefectural cities in Hunan is more than 1, which indicates that the stability of ecological system of all prefectural cities in Hunan is preferable. The ecological footprint diversity index of Changsha and Loudi is the highest, and the annual average is 1.27 , which is at a relatively high level. The ecological footprint diversity index of Changsha and Loudi in 2005-2015 was greater than 1, and its distribution was between 1.18 1.45 and 1.09 1.40, which indicates that the distribution of ecological footprint among different types of biological productivity land in Changsha and Loudi are more uniform, and the stability of the ecosystem is also the best, compared with other cities (states). It is worth noting that the annual average of ecological footprint diversity index of Xiangxi and Huaihua is 0.76 and 0.88 , respectively. Investigating its cause, the proportion of the hydropower ecological footprint of Huaihua is too large, the proportion is more than $54 \%$, and the proportion of forest ecological footprint of Xiangxi is too large, with its proportion is more than $54 \%$.

The trend shows that the ecological footprint diversity index of most cities increased from 2005 to 2015, indicating that the coordination between urban economic development and ecological environment is gradually improving. However, the diversity index of Huaihua declined obviously, which indicated that its economic development has caused certain damage to the ecological environment, and it is necessary to develop the economy under the premise of protecting the ecological environment well. The ecological footprint diversity index of Xiangxi Autonomous Prefecture is relatively low, but it has been relatively stable all the time. This is closely related to the fact that it is a fragile ecological region and a key ecological functional area of the country. The forest is developed while other ecologically productive land is restricted, thus the trend of ecological footprint is stable.

The eco-economic development capacity index calculated based on the Formula (5) is a favorable index to reflect the development of regional eco-economic system. Table 3 shows that the level of eco-economic development capacity of all prefecture-level cities in Hunan is relatively low, and the highest is Yongzhou whose average development ability index is 1.50 NHA. The lowest is Xiangtan whose average development ability index is only $0.49 \mathrm{NHA}$, which may be related to the old industrial base of Xiangtan and its weak system reform. In addition, the development capacity index of most cities showed an upward trend in 2005-2015. This shows that the ecological and economic development of the region is gradually improving.

\subsection{Analysis of the Ecological Efficiency in Hunan}

The ecological efficiency of Hunan is calculated by using the Formula (6), and the results are shown in Figure 7. It shows that the ecological efficiency is improving continuously, and its value is increased from $1.591 \times 10^{5}$ Yuan/NHA (GDP is calculated by constant price in 2005) to $5.456 \times 10^{5}$ Yuan/NHA, with an average annual growth rate of $13.12 \%$.

Table 4 shows that the ecological efficiency of each city is difference. The regions with high ecological efficiency are mainly concentrated in Changsha-Zhuzhou-Xiangtan urban agglomeration and its surrounding cities. Changsha is observed the highest ecological efficiency (6.51), while Huaihua is the lowest (0.70). Thus, the annual average of ecological efficiency in Changsha is 9.3 times higher than that in Huaihua. For the growth rate of ecological efficiency, five cities (Changsha, Zhuzhou, Yueyang, Loudi, and Xiangxi) increase year by year; Xiangtan, Shaoyang, Changde, and Huaihua increase first and then decrease; Hengyang decreases gradually; Yiyang decreases first and then increases. 


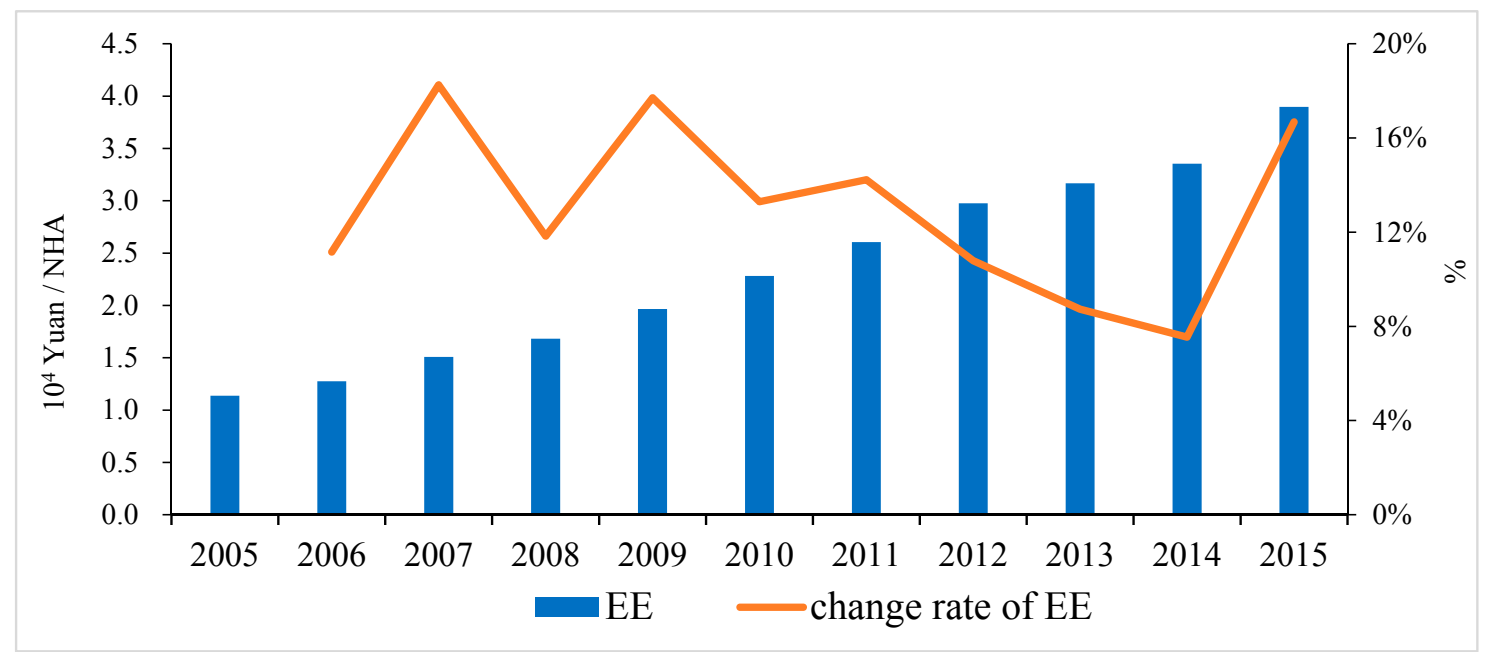

Figure 7. Ecological efficiency of Hunan Province in 2005-2015.

Table 4. Ecological efficiency and rate of change in main years of Hunan Province.

\begin{tabular}{c|cccc|cccc}
\hline \multirow{2}{*}{ District } & \multicolumn{4}{|c|}{ EE } & \multicolumn{4}{c}{ Change Rate of EE (\%) } \\
\cline { 2 - 8 } & $\mathbf{2 0 0 5}$ & $\mathbf{2 0 1 0}$ & $\mathbf{2 0 1 5}$ & Mean & $\mathbf{2 0 0 6}$ & $\mathbf{2 0 1 0}$ & $\mathbf{2 0 1 5}$ & Mean \\
\hline Changsha & 3.13 & 6.17 & 10.39 & 6.51 & 14.05 & 21.17 & 16.55 & 13.16 \\
Zhuzhou & 1.38 & 3.25 & 4.73 & 2.93 & 6.75 & 11.27 & 23.94 & 17.48 \\
Xiangtan & 2.65 & 6.27 & 10.70 & 6.35 & 20.64 & 20.90 & 8.58 & 15.12 \\
Hengyang & 0.96 & 1.53 & 2.97 & 1.84 & 9.48 & -1.56 & -0.20 & 12.47 \\
Shaoyang & 0.54 & 1.14 & 1.74 & 1.11 & 10.78 & 21.74 & 15.25 & 12.51 \\
Yueyang & 1.04 & 2.20 & 4.80 & 2.57 & 11.84 & 18.31 & 20.20 & 16.87 \\
Changde & 0.93 & 1.85 & 3.07 & 1.85 & 8.61 & 17.97 & 13.91 & 12.85 \\
Zhangjiajie & 0.85 & 1.33 & 2.41 & 1.47 & 18.72 & 4.93 & 7.31 & 11.24 \\
Yiyang & 0.62 & 0.88 & 1.70 & 0.99 & 36.19 & 16.55 & 48.28 & 12.44 \\
Chenzhou & 0.86 & 1.60 & 3.12 & 1.68 & 5.64 & 23.17 & 15.49 & 14.18 \\
Yongzhou & 0.53 & 0.95 & 1.40 & 0.94 & 10.25 & -0.24 & 14.96 & 10.78 \\
Huaihua & 0.44 & 0.70 & 0.86 & 0.70 & 2.44 & 9.79 & 5.03 & 7.58 \\
Loudi & 1.49 & 3.44 & 5.58 & 3.22 & 1.04 & 19.55 & 38.47 & 16.96 \\
Xiangxi & 0.48 & 0.63 & 1.10 & 0.72 & -0.28 & 2.56 & 5.75 & 8.64 \\
\hline
\end{tabular}

Furthermore, using Formula (8), the change of ecological efficiency can be decomposed into two parts: the change of total factor productivity and the change of factor substitution, and the former is equal to the technological progress change multiply by the technological efficiency change. The ecological footprint (EF) has been calculated. The capital stock $(K)$ is calculated by the method of perpetual inventory (the unit is 100 million yuan which calculated at the constant price on 2005); the labor input $(L)$ is the number of employees (tens of thousands of people). The results of decomposition are shown in Figure 8.

As shown in Figure 8a, during the sample period, the factor substitution rate is always positive, indicating that the ecological capital is replaced by labor and capital stock, or people tend to economize ecological capital to develop economy, which helps to improve ecological efficiency. Furthermore, the change of factor substitution rate is greater than that of total factor productivity. In other words, the improvement of ecological efficiency is mainly due to the improvement of factor substitution rate, which also shows that the fluctuation trend of factor substitution rate is basically consistent with that of ecological efficiency (Figure 7). It is worth noting that the factor substitution rate showed a rapid downward trend from 2009 to 2013. The main reason is that in order to cope with the financial crisis in 2008, Hunan adopted measures to cope with large-scale investment, which led to a resource-intensive industrial structure. To some extent, it has worsened the change of element substitution and hindered the improvement of ecological efficiency. 


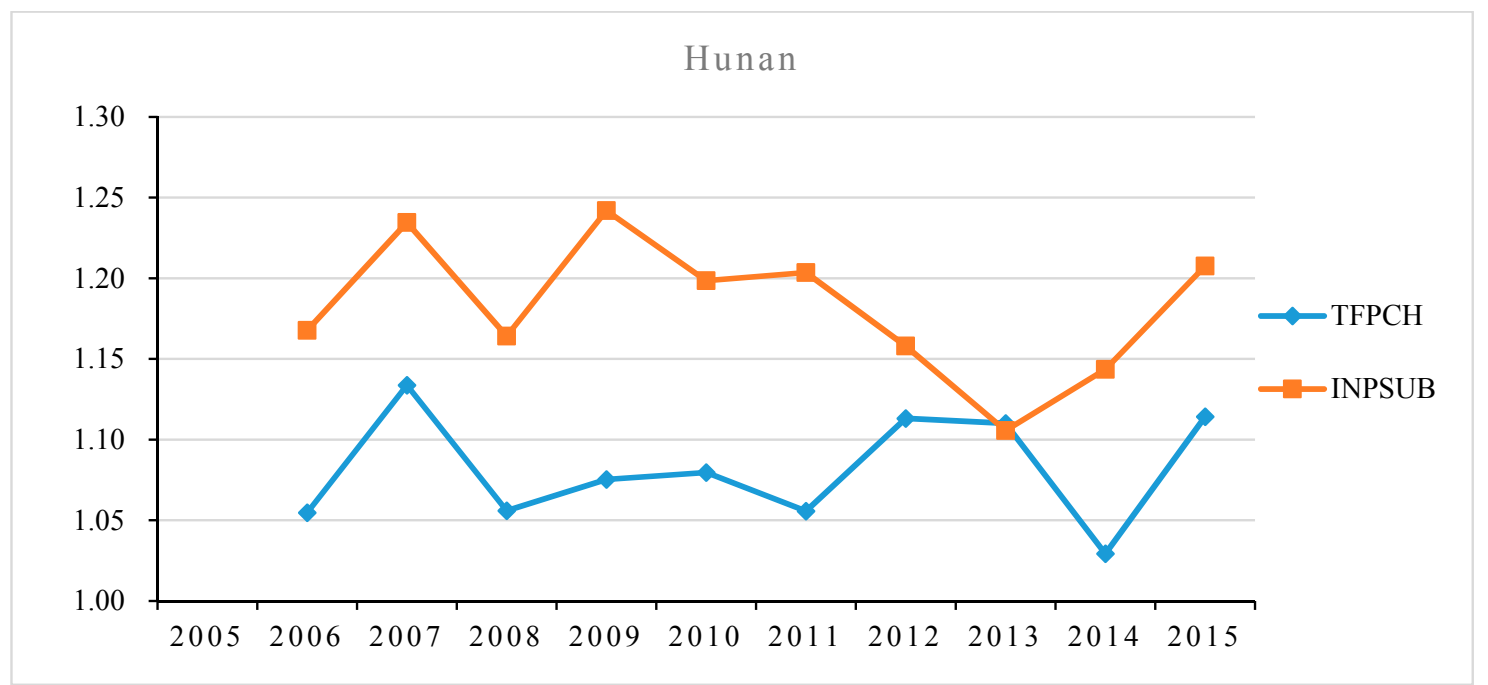

(a) Factor decomposition of ecological efficiency changes in Hunan Province in 2005-2015

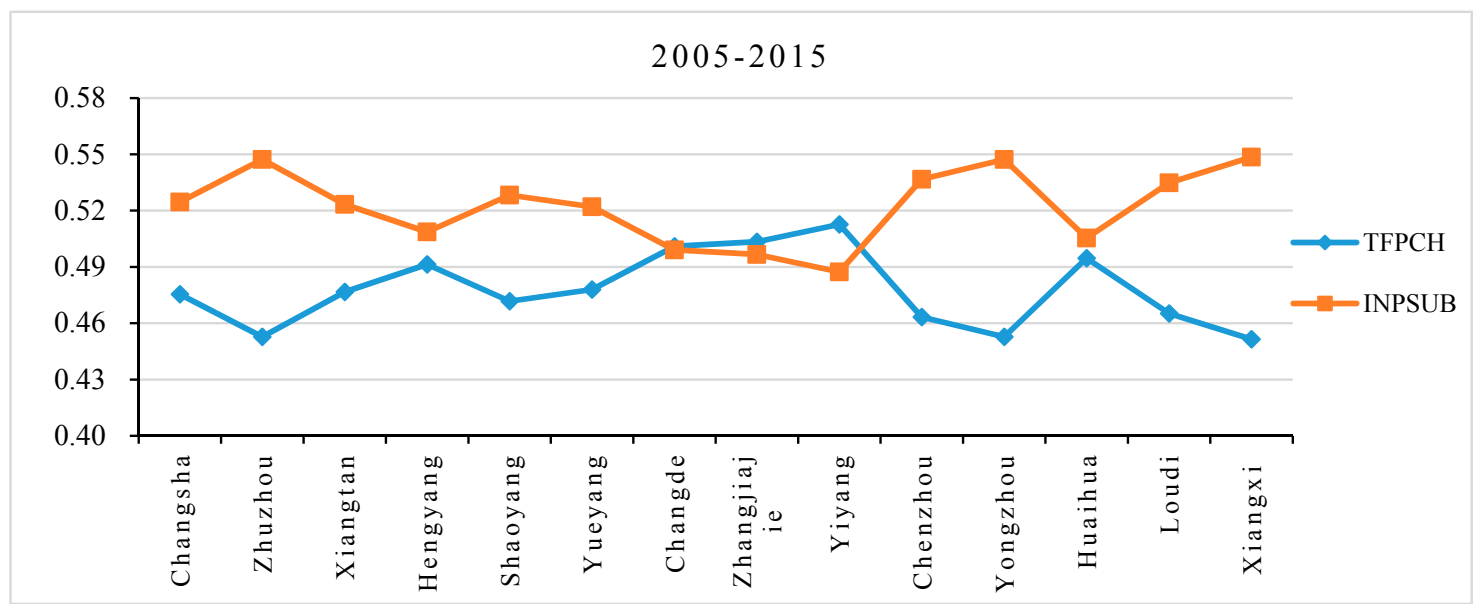

(b) Factor decomposition of ecological efficiency changes in cities in2005-2015

Figure 8. Factor decomposition of ecological efficiency changes.

Figure $8 \mathrm{~b}$ shows the average annual change in total factor productivity and factor substitution rate in each city from 2005 to 2015. Obviously, the change in factor substitution rate is the main reason for the improvement of ecological efficiency in most cities. However, the improvement of ecological efficiency in Changde, Zhangjiajie, and Yiyang is mainly due to the increase in total factor productivity.

\section{Conclusions}

Hunan is an important experimental area for the construction of ecological civilization in China, and its green development index ranks the forefront in the country. Based on the three-dimensional ecological model, this paper adopts ecological footprint, ecological carrying capacity, ecological footprint depth and size, ecological diversity index, eco-economy development capacity index, and the GDP in per unit ecological footprint (ecological efficiency) to comprehensively measure and evaluate the ecological sustainable development of Hunan from 2005 to 2015. The main conclusions of this paper are as follows:

1. The total ecological footprint of Hunan fluctuant increased from 2005 to 2015 , and the ecological footprint of forest land accounted for $57.1 \%$ of the total ecological footprint; arable land and construction land are also important contributors to the ecological footprint of Hunan. The proportion of carbon footprint is small and shows a slow downward trend. This is mainly 
due to the fact that the carbon dioxide emissions of Hunan are smaller than the national average, and Hunan is actively promoting the development of low-carbon industries. Additionally, the ecological carrying capacity of Hunan remained basically stable in 2005-2015. The per capita ecological footprint size and depth increased first then decreased, and the ecological footprint depth is always greater than 1. Based on the above analysis, Hunan has been in a state of ecological deficit, and natural capital flow is not sufficient to meet consumption demand. In other words, ecological capital stock needs to be consumed to maintain development.

2. The ecological footprint diversity index of most prefecture-level cities in Hunan shows an upward trend and is greater than 1, indicating that the coordination between economic development and ecological environment in Hunan has gradually improved, and the ecosystem is stable. Because the composition of ecological footprint in Huaihua and Xiangxi is unbalanced and the proportion of forest land and hydropower is too high, so the ecological footprint diversity index is lower than 1 . The result of ecological economy development capacity shows that the level of ecological economy development ability of prefecture-level cities is low but present an improvement tendency.

3. From the perspective of spatial distribution, the per capita ecological footprint of Hunan shows a pattern of "high in surround, low in the central". The high value areas are mainly distributed in western Hunan and northern Hunan, and the low value areas are mainly distributed in central Hunan such as Xiangtan and Loudi. The distribution patterns of per capita ecological carrying capacity and per capita ecological footprint are similar, which is related to the stable distribution of arable land in Hunan.

4. The ecological efficiency of Hunan increases with an average rate of $13.12 \%$ annually, but there are obvious differences among prefecture-level cities. The regions with high ecological efficiency are mainly Changsha-Zhuzhou-Xiangtan urban agglomeration and its surrounding areas, and the regions with low ecological efficiency are mainly distributed in western Hunan. It is found that the main reason for the improvement of ecological efficiency of Hunan is the improvement of the factor substitution rate, that is, the ecological capital is replaced by the capital stock and labor input.

Author Contributions: K.L. and C.D. designed this study and participated in all phases; Z.L. analyzed the data and wrote the manuscript; R.L. analyzed the data and drew all figures. All authors read and approved the final manuscript.

Funding: This research is supported by the National Natural Science Foundation of China (No. 71773028), the education department of Hunan province (17A142), the International Clean Energy Talent Programme (No. LIUJINFA[2017]5047-201702660011), the National Social Science Foundation Project of China(No. 16BJL063), and the Key Project of Hunan Social Science Foundation (No. 16ZDB014).

Conflicts of Interest: The authors declare no conflict of interest.

\section{Nomenclature}

$\begin{array}{ll}\text { Acronyms } & \\ \text { EF } & \text { ecological footprint } \\ \text { EPI } & \text { ecological pressure index } \\ \text { CEPI } & \text { consumption footprint pressure index } \\ \text { PFPI } & \text { production footprint pressure index } \\ \text { EFCI } & \text { ecological footprint contribution index } \\ \text { NPP } & \text { net primary productivity } \\ \text { BTH } & \text { the Beijing-Tianjin-Hebei } \\ \text { ETI } & \text { ecological tension index } \\ \text { EOI } & \text { ecological occupancy index } \\ \text { EECI } & \text { ecological economic coordination index } \\ \text { CHANS } & \text { coupled human and natural systems } \\ \text { EV } & \text { ecosystem vigor }\end{array}$




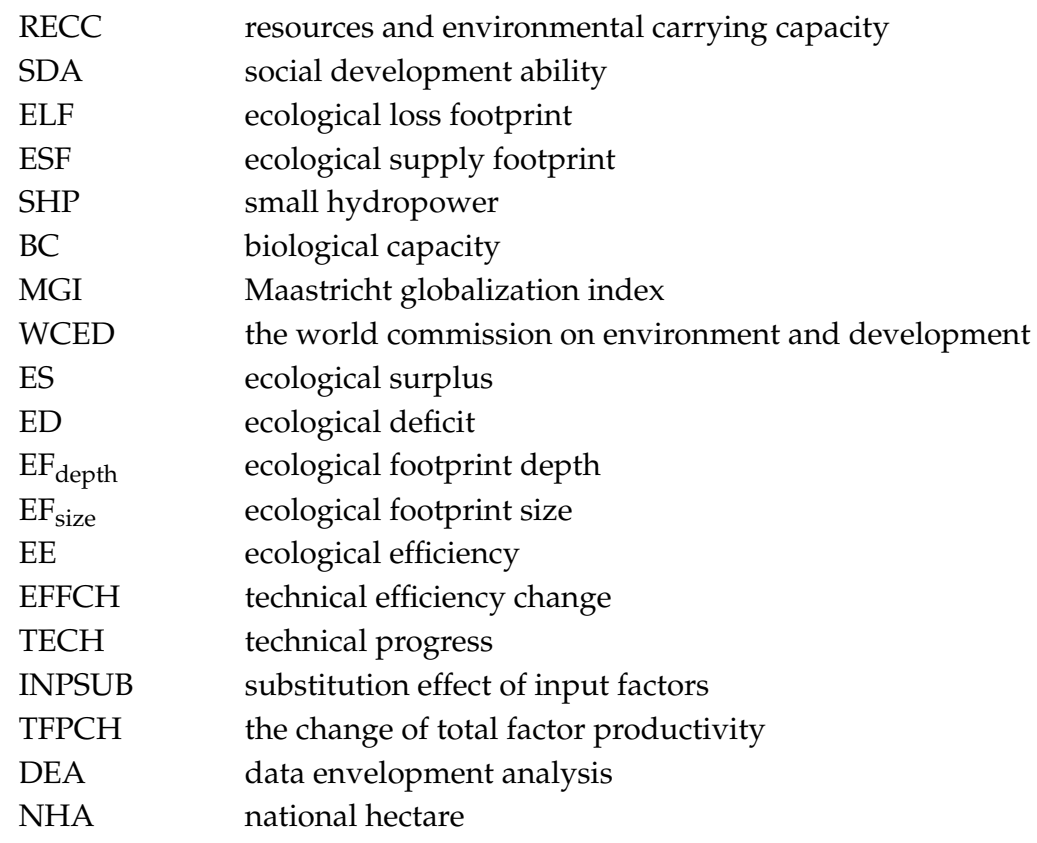

\section{Appendix A}

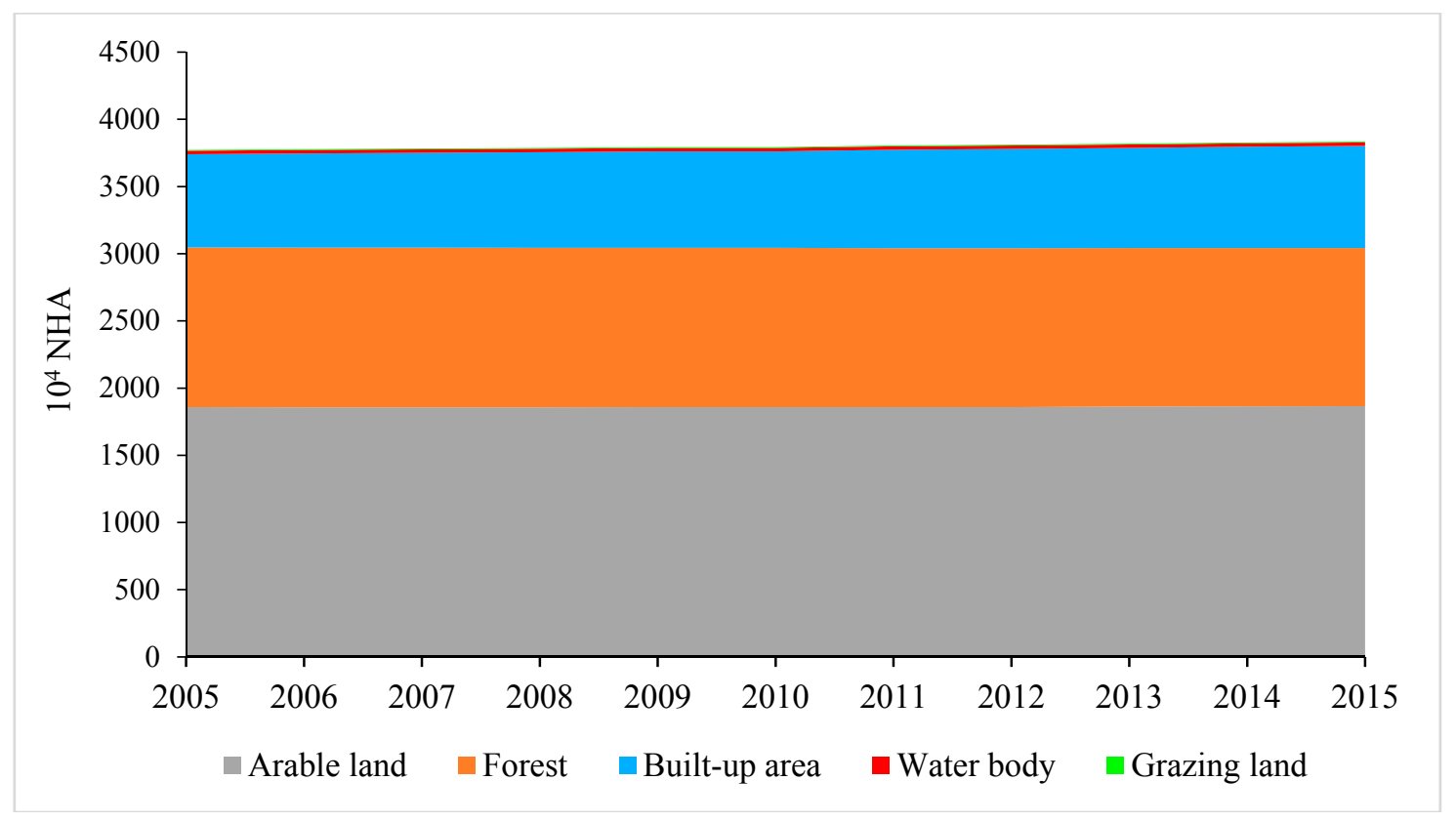

Figure A1. Composition of ecological carrying capacity in Hunan Province in 2005-2015. 

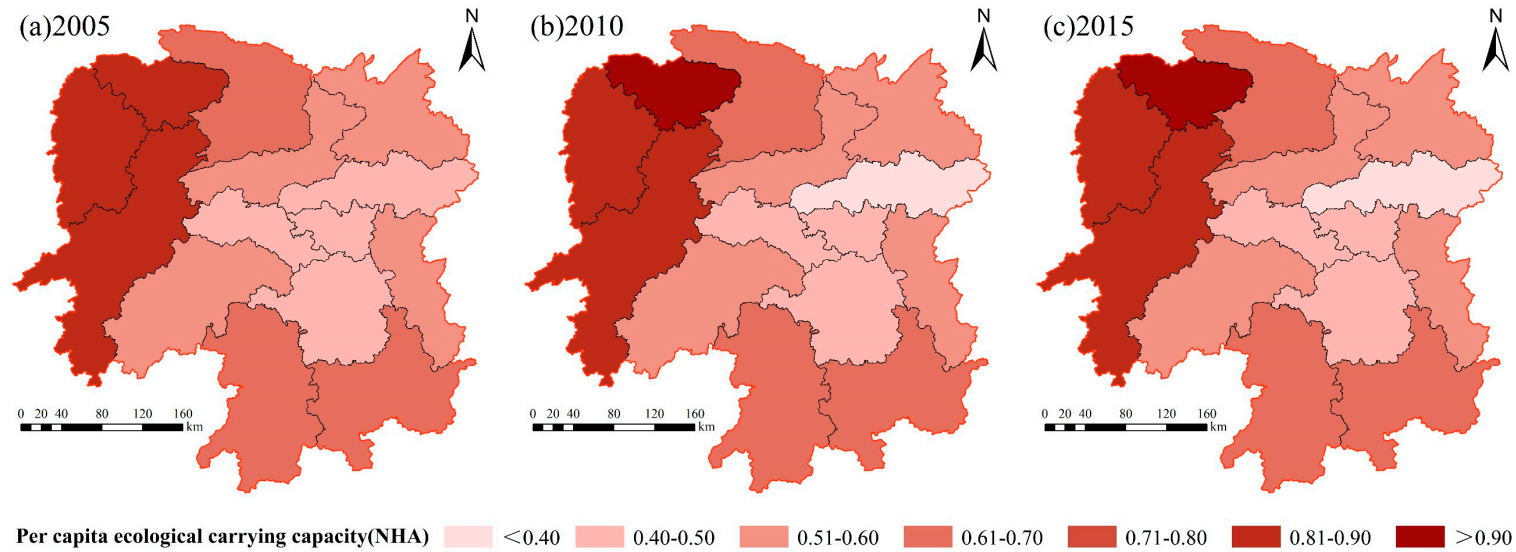

Figure A2. Per capita ecological carrying capacity of Hunan Province (NHA/person).

\section{References}

1. Wackemagel, M.; Rees, W.E. Perceptual and structural barriers to investing in natural capital: Economics from an ecological footprint perspective. Ecol. Econ. 1997, 20, 3-24. [CrossRef]

2. Fu, W.; Turner, J.C.; Zhao, J.; Du, G. Ecological footprint (EF): An expanded role in calculating resource productivity (RP) using China and the G20 member countries as examples. Ecol. Indic. 2015, 48, 464-471. [CrossRef]

3. Yue, S.; Yang, Y.; Shao, J.; Zhu, Y. International Comparison of Total Factor Ecology Efficiency: Focused on G20 from 1999-2013. Sustainability 2016, 8, 1129. [CrossRef]

4. Ozturk, I.; Al-Mulali, U.; Saboori, B. Investigating the environmental Kuznets curve hypothesis: The role of tourism and ecological footprint. Environ. Sci. Pollut. Res. Int. 2016, 23, 1916-1928. [CrossRef] [PubMed]

5. Siche, R.; Pereira, L.; Agostinho, F.; Ortega, E. Convergence of ecological footprint and emergy analysis as a sustainability indicator of countries: Peru as case study. Commun. Nonlinear Sci. Numer. Simul. 2010, 15, 3182-3192. [CrossRef]

6. Wu, D.; Liu, J. Multi-Regional Input-Output (MRIO) Study of the Provincial Ecological Footprints and Domestic Embodied Footprints Traded among China's 30 Provinces. Sustainability 2016, 8, 1345. [CrossRef]

7. He, Y.; Che, T.; Wang, Y. Ecological Footprint and Endogenous Economic Growth in the Poyang Lake Area in China Based on Empirical Analysis of Panel Data Model. J. Resour. Ecol. 2012, 3, 367-372.

8. Wang, S.; Yang, F.-L.; Xu, L.; Du, J. Multi-scale analysis of the water resources carrying capacity of the Liaohe Basin based on ecological footprints. J. Clean. Prod. 2013, 53, 158-166. [CrossRef]

9. Li, X.; Tian, M.; Wang, H.; Wang, H.; Yu, J. Development of an ecological security evaluation method based on the ecological footprint and application to a typical steppe region in China. Ecol. Indic. 2014, 39, 153-159. [CrossRef]

10. Gu, Q.; Wang, H.; Zheng, Y.; Zhu, J.; Li, X. Ecological footprint analysis for urban agglomeration sustainability in the middle stream of the Yangtze River. Ecol. Model. 2015, 318, 86-99. [CrossRef]

11. Li, J.; Liu, Z.; He, C.; Tu, W.; Sun, Z. Are the drylands in northern China sustainable? A perspective from ecological footprint dynamics from 1990 to 2010. Sci. Total Environ. 2016, 553, 223-231. [CrossRef] [PubMed]

12. Yin, Y.; Han, X.; Wu, S. Spatial and Temporal Variations in the Ecological Footprints in Northwest China from 2005 to 2014. Sustainability 2017, 9, 597. [CrossRef]

13. Xie, Z.; Gao, Y.; Li, C.; Zhou, J.; Zhang, T. Spatial Heterogeneity of Typical Ecosystem Services and Their Relationships in Different Ecological-Functional Zones in Beijing-Tianjin-Hebei Region, China. Sustainability 2017, 10, 6. [CrossRef]

14. Chu, X.; Deng, X.; Jin, G.; Wang, Z.; Li, Z. Ecological security assessment based on ecological footprint approach in Beijing-Tianjin-Hebei region, China. Phys. Chem. Earthparts A/B/C 2017, 101, 43-51. [CrossRef]

15. Wang, M.; Liu, J.; Wang, J.; Zhao, G. Ecological footprint and major driving forces in West Jilin Province, Northeast China. Chin. Geogr. Sci. 2010, 20, 434-441. [CrossRef]

16. He, J.; Wan, Y.; Feng, L.; Ai, J.; Wang, Y. An integrated data envelopment analysis and emergy-based ecological footprint methodology in evaluating sustainable development, a case study of Jiangsu Province, China. Ecol. Indic. 2016, 70, 23-34. [CrossRef] 
17. Miao, C.-L.; Sun, L.-Y.; Yang, L. The studies of ecological environmental quality assessment in Anhui Province based on ecological footprint. Ecol. Indic. 2016, 60, 879-883. [CrossRef]

18. Wang, Y.; Li, X.; Li, J. Study on the response of ecological capacity to land-use/cover change in Wuhan city: A remote sensing and GIS based approach. Sci. World J. 2014, 2014, 794323. [CrossRef] [PubMed]

19. Yao, X.; Wang, Z.; Zhang, H. Dynamic Changes of the Ecological Footprint and Its Component Analysis Response to Land Use in Wuhan, China. Sustainability 2016, 8, 329. [CrossRef]

20. Wang, F.; Wang, K. Assessing the Effect of Eco-City Practices on Urban Sustainability Using an Extended Ecological Footprint Model: A Case Study in Xi'an, China. Sustainability 2017, 9, 1591. [CrossRef]

21. Li, Y.; Zhan, J.; Zhang, F.; Zhang, M.; Chen, D. The study on ecological sustainable development in Chengdu. Phys. Chem. Earthparts A/B/C 2017, 101, 112-120. [CrossRef]

22. Fan, Y.; Qiao, Q.; Xian, C.; Xiao, Y.; Fang, L. A modified ecological footprint method to evaluate environmental impacts of industrial parks. Resour. Conserv. Recycl. 2017, 125, 293-299. [CrossRef]

23. Zhen, L.; Du, B. Ecological Footprint Analysis Based on Changing Food Consumption in a Poorly Developed Area of China. Sustainability 2017, 9, 1323. [CrossRef]

24. Dai, L.; Xu, B.; Wu, B. Assessing sustainable development of a historic district using an ecological footprint model: A case study of Nanluoguxiang in Beijing, China. Area 2017, 49, 94-105. [CrossRef]

25. Chen, J.; Ye, G.; Jing, C.; Wu, J.; Ma, P. Ecological footprint analysis on tourism carrying capacity at the Zhoushan Archipelago, China. Asia Pac. J. Tour. Res. 2017, 22, 1049-1062. [CrossRef]

26. Chen, H.S. Evaluation and Analysis of Eco-Security in Environmentally Sensitive Areas Using an Emergy Ecological Footprint. Int J Env. Res Public Health 2017, 14, 136. [CrossRef] [PubMed]

27. Tian, M. Study on Sustainable Development of Agriculture in Dabieshan Pilot Site Based on the Model of Ecological Footprint. Int. J. Environ. Prot. Policy 2015, 3, 124-128. [CrossRef]

28. Peng, J.; Du, Y.; Liu, Y.; Hu, X. How to assess urban development potential in mountain areas? An approach of ecological carrying capacity in the view of coupled human and natural systems. Ecol. Indic. 2016, 60, 1017-1030. [CrossRef]

29. Wang, Y.; Wang, L.; Shao, H. Ecological Footprint Analysis Applied to a Coal-Consumption County in China. Clean Soil Air Water 2014, 42, 1004-1013. [CrossRef]

30. Bai, X.; Wen, Z.; An, S.; Li, B. Evaluating sustainability of cropland use in Yuanzhou county of the Loess plateau, China using an emergy-based ecological footprint. PLoS ONE 2015, 10, e0118282. [CrossRef] [PubMed]

31. Wang, J.; Zhang, Q.; Zou, C. Dynamic evolutions of ecological carrying capacity in poor areas using ecological footprint model at Ruyang County of China. Int. J. Agric. Biol. Eng. 2017, 10, 140-150.

32. Dang, X.; Liu, G.; Xue, S.; Li, P. An ecological footprint and emergy based assessment of an ecological restoration program in the Loess Hilly Region of China. Ecol. Eng. 2013, 61, 258-267. [CrossRef]

33. Wei, X.Y.; Xia, J.X. Ecological compensation for large water projects based on ecological footprint theory: A case study in China. Procedia Environ. Sci. 2012, 13, 1338-1345. [CrossRef]

34. Wang, C.; Shi, G.; Wei, Y.; Western, A.; Zheng, H.; Zhao, Y. Balancing Rural Household Livelihood and Regional Ecological Footprint in Water Source Areas of the South-to-North Water Diversion Project. Sustainability 2017, 9, 1393. [CrossRef]

35. Wang, Z.; Li, Q.; Huang, Z.; Tang, X.; Zhao, W. Ecological footprint analysis of environmental impacts by cascaded exploitation of diversion-type small hydropower: A case study in southwest china. Iop Conf. Ser. Earth Environ. Sci. 2017, 64, 012056. [CrossRef]

36. Hu, J.; Zhen, L.; Sun, C.-Z.; Du, B.-Z.; Wang, C. Ecological Footprint of Biological Resource Consumption in a Typical Area of the Green for Grain Project in Northwestern China. Environments 2015, 2, 44-60. [CrossRef]

37. Wu, X.F.; Yang, Q.; Xia, X.H.; Wu, T.H.; Wu, X.D.; Shao, L.; Hayat, T.; Alsaedi, A.; Chen, G.Q. Sustainability of a typical biogas system in China: Emergy-based ecological footprint assessment. Ecol. Inform. 2015, 26, 78-84. [CrossRef]

38. Liu, X.; Jiang, D.; Wang, Q.; Liu, H.; Li, J.; Fu, Z. Evaluating the Sustainability of Nature Reserves Using an Ecological Footprint Method: A Case Study in China. Sustainability 2016, 8, 1272. [CrossRef]

39. Chen, D.-D.; Gao, W.-S.; Chen, Y.-Q.; Zhang, Q. Ecological footprint analysis of food consumption of rural residents in China in the latest 30 years. Agric. Agric. Sci. Procedia 2010, 1, 106-115. [CrossRef]

40. Song, G.; Li, M.; Semakula, H.M.; Zhang, S. Food consumption and waste and the embedded carbon, water and ecological footprints of households in China. Sci. Total Environ. 2015, 529, 191-197. [CrossRef] [PubMed] 
41. Lazarus, E.; Lin, D.; Martindill, J.; Hardiman, J.; Pitney, L.; Galli, A. Biodiversity Loss and the Ecological Footprint of Trade. Diversity 2015, 7, 170-191. [CrossRef]

42. Figge, L.; Oebels, K.; Offermans, A. The effects of globalization on Ecological Footprints: An empirical analysis. Environ. Dev. Sustain. 2016, 19, 863-876. [CrossRef]

43. Gao, J.; Tian, M. Analysis of over-consumption of natural resources and the ecological trade deficit in China based on ecological footprints. Ecol. Indic. 2016, 61, 899-904. [CrossRef]

44. Niccolucci, V.; Galli, A.; Reed, A.; Neri, E.; Wackernagel, M.; Bastianoni, S. Towards a 3D National Ecological Footprint Geography. Ecol. Model. 2011, 222, 2939-2944. [CrossRef]

45. Fang, K. Ecological footprint depth and size: New indicators for a 3D model. Acta Ecol. Sin. 2013, 33, $267-274$. [CrossRef]

46. Peng, J.; Du, Y.; Ma, J.; Liu, Z.; Liu, Y.; Wei, H. Sustainability evaluation of natural capital utilization based on 3DEF model: A case study in Beijing City, China. Ecol. Indic. 2015, 58, 254-266. [CrossRef]

47. National Economic and Social Development Bulletin of Hunan Province in $2015 . \quad$ (In Chinese). Available online: http://www.ha.stats.gov.cn/sitesources/hntj/page_pc/tjfw/tjgb/gjhgsgb/ article656d9778f3764987a8f6413edb093bb2.html (accessed on 26 November 2018).

48. Geographical Situation. Hunan Provincial People's Government. (In Chinese). Available online: http:/ / www.hunan.gov.cn (accessed on 26 November 2018).

49. Wackernagel, M.; Onisto, L.; Bello, P.; Linares, A.C.; Falfan, I.S.L.; Garc1A, J.M.; Guerrero, A.I.S.; Ma, G.S.G. National natural capital accounting with the ecological footprint concept. Ecol. Econ. 1999, 29, 375-390. [CrossRef]

50. Yang, Y.; Hu, D. Natural capital utilization based on a three-dimensional ecological footprint model: A case study in northern Shaanxi, China. Ecol. Indic. 2018, 87, 178-188. [CrossRef]

51. Ulanowicz, R.E. Growth and Development: Ecosystems Phenomenology; Springer: New York, NY, USA, 1986.

52. Färe, R.; Grosskopf, S.; Norris, M.; Zhang, Z. Productivity Growth, Technical Progress, and Efficiency Change in Industrialized Countries. Am. Econ. Rev. 1994, 84, 66-83.

53. Li, K.; Lin, B. How to promote energy efficiency through technological progress in China? Energy 2018, 143, 812-821. [CrossRef]

54. Wackernagel, M.; White, S.; Moran, D. Using ecological footprint accounts: From analysis to applications. Int. J. Environ. Sustain. Dev. 2004, 3, 293-315. [CrossRef]

55. Xun, F.; Hu, Y. Evaluation of ecological sustainability based on a revised three-dimensional ecological footprint model in Shandong Province, China. Sci. Total Environ. 2019, 649, 582-591. [CrossRef] [PubMed] 